\title{
Nueva ruralidad en la Huasteca poblana: otomíes y nahuas de Pahuatlán (1960-2010)
}

\section{New Rurality in the Huasteca Poblana: Otomies and Nahuas of Pahuatlán (1960-2010)}

\section{Libertad Mora Martínez}

FACULTAD DE ARTES, BENEMÉRITA UNIVERSIDAD AUTÓNOMA DE PUEBLA / PIRED AC, libertad_mora@enah.edu.mx

Este artículo tiene como objetivo dar cuenta de una serie de cambios en la economía de dos comunidades indígenas, nahua y otomí, en un mismo municipio (Pahuatlán) de la región Huasteca poblana. El análisis comprende el periodo que va de los ańos sesenta del siglo pasado a la primera década del nuevo milenio. La producción agrícola y su comercialización han pasado a segundo término entre las estrategias de reproducción de la unidad doméstica, superadas por la actividad artesanal, la movilidad laboral y la migración transnacional. Con el enfoque de la nueva ruralidad se propone revisar cuáles han sido las alternativas de subsistencia nahuas y otomíes durante ese tiempo, qué nuevos procesos se han gestado, así como quiénes fueron y son los partícipes de unas y otras actividades.

PALABRAS ClaVE: nueva ruralidad, campesino, movilidad, migración, Huasteca poblana.

The objective of this article is to explain a series of changes in the economy of two indigenous communities -Nahua and Otomí- living in the same municipality (Pahuatlán) in the Huasteca region of Puebla. The analysis spans the period from the 1960s to the first decade of the new millennium, during which agricultural production and commercialization were surpassed in importance by artisanal activities, labor mobility and transnational migration. Using the New Rurality approach, we set out to examine the options for subsistence that these Nahua and Otomi adopted during the study period, the processes that were generated, and the identities of participants in the different activities.

KEYwORDS: new rurality, peasantry, mobility, transnational migration, Huasteca, Puebla.

Fecha de recepción: 26 de enero de 2016 / Fecha de aceptación: 17 de febrero de 2017 / Fecha de versión definitiva: 8 de mayo de 2017

\section{LA DISPUTA TEÓRICA}

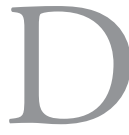

esde un enfoque antropológico, dar cuenta de las alternativas económicas que imperan en los contextos rurales del país remite a una serie de procesos novedosos en los cuales 
están inmersos indígenas y mestizos. La pluriactividad no es un fenómeno exclusivo de este milenio. La gente que habita en zonas rurales ha subsistido desde tiempos remotos gracias a combinar varias actividades para satisfacer sus necesidades básicas. Pese a ello, algunos estudios antropológicos y de sociología rural han realizado sus análisis homologando el sujeto a una sola vía: el campesino ligado a la producción agrícola. Incluso ocurre que la gente que ya no se dedica a esa actividad, se le sigue considerando campesina. Esto puede obedecer a distintas causas: o bien el concepto de "campesino" remite a un campo semántico amplio e impreciso que no refiere exclusivamente a la actividad agrícola, o bien ocurre que los académicos no guardan interés por dar cuenta de la realidad social. En ese sentido, me parece, se debe ser claro en la "pertinencia empírica de los términos". ${ }^{1}$

Como sugiere David Skerritt, campesino es una categoría que presenta varios problemas a pesar de su aparente sencillez. “¿De qué hablamos cuando utilizamos el término campesino, sea como sustantivo sea como adjetivo?"2 En ese tenor, cuestionarnos acerca de qué sujetos estamos hablando, y de las condiciones precisas de su contexto, resulta no sólo útil en términos prácticos para los análisis académicos, sino incluso ético y necesario para dar cuenta de la realidad social; una realidad que se caracteriza por la diversidad cultural, la cohabitación de diferentes grupos en espacios de fronteras porosas, el papel preponderante de las tecnologías de información y comunicación en contextos de globalización.

$\mathrm{Al}$ respecto, habrá que recordar la postura crítica de Michael Kearney, quien propone "no sólo repensar el concepto de campesino sino incluso [...] reemplazarlo por términos que se adecuen mejor a las dinámicas y características de la vida rural moderna”. ${ }^{3} \mathrm{~A}$

${ }^{1}$ Jairo Tocancipá-Falla, "El retorno de lo campesino: una revisión sobre los esencialismos y heterogeneidades en la antropología", Revista Colombiana de Antropología (41) (2005): 9.

${ }^{2}$ David Skerritt Gardner, Campesinos: ¿de qué hablamos? (Xalapa: IIHs, uv, 1998), 4.

${ }^{3}$ Julio Mario Palacios Urueta, "Movimiento campesino en el sur de Santander. Una lucha por el acceso a la modernidad" (Tesis de maestría en Antropología Visual y Documental Antropológico, FLACso Ecuador, 2013), 18; Michael Kearney, Reconceptualizing the Peasantry: Anthropology in Global Perspective (Boulder: Westview Press, 1996). 
partir de ello, sugiere cambiar el término peasantry (campesino) por polybians (poly = muchos; bios = vida, modos de vida), con el cual pretende dar cuenta de la diversidad de alternativas de subsistencia económica y la variedad de sitios en los cuales los grupos pueden vivir. Es decir que no resulta obligado, ni siquiera frecuente, que las personas estén fijas en un sólo lugar, y tampoco que se dediquen a una sola actividad económica. Sin embargo, esta propuesta despertó ciertos reparos. Uno de ellos fue señalado por Eric Wolf, quien insistía en diferenciar los conceptos empleados en el análisis, de aquéllos utilizados en la descripción; o bien, de la propia identificación de la gente, es decir, cómo y con qué actividades se reconocen los actores sociales. ${ }^{4}$ En la misma sintonía, aunque puntualizando aún más el debate, el antropólogo colombiano Jairo Tocancipá-Falla señala lo siguiente:

el uso de los términos también posee una relación, continuidad y permanencia que se vincula con otras dimensiones en lo político, lo económico y lo social. Es comprensible entonces que Kearney trate de desechar el concepto de peasantry y sustituirlo por otro que refleje con más agudeza la realidad social que estudia. Sin embargo, su invención no es una manifestación del uso social por parte de los actores que experimentan los cambios sociales y económicos, ni es parte del proceso de representación que tienen de sí mismos. ${ }^{5}$

En este punto conviene considerar la propuesta de Wolf, quien "reconoce al campesinado como un grupo social no sólo desde el punto de vista económico, sino en su aspecto simbólico", ${ }^{6}$ y señala que "el objetivo principal del campesino es la subsistencia y el estatus social que se obtiene dentro de un pequeńo campo de relaciones sociales". ' La interrogante, entonces, se reitera: ¿`cómo se identifican

${ }^{4}$ Palacios, "Movimiento campesino", 20; Eric R. Wolf, Las luchas campesinas del siglo $X X$, trad. Roberto Reyes Mazzoni (México: Siglo XXI, 1999).

${ }^{5}$ Tocancipá-Falla, "Retorno de lo campesino", 15.

${ }^{6}$ Tania Jeanine Wuest Silva, “¿Nueva Ruralidad en México?” (Tesis de licenciatura en Sociología, UAM, 2004), 14; Eric R. Wolf, Los campesinos (Barcelona: Labor, 1987).

${ }^{7}$ Wolf, Luchas campesinas, 10, citado en Palacios, "Movimiento campesino", 23. 
los actores sociales? En este caso en particular: ¿cómo se han identificado los nahuas de Xolotla y cómo los otomíes de San Pablito, ambos en el municipio de Pahuatlán? ¿Cuáles son las estrategias de subsistencia en distintos momentos entre ambos grupos?

Este trabajo busca dar cuenta de las alternativas económicas que han persistido en una porción de la región geográfica-cultural del país conocida como Huasteca poblana, así como de los procesos locales que a partir de éstas se han gestado. Se trata de un esbozo general de las actividades económicas que se abandonaron, las que se mantienen y las que se han comenzado a practicar. Abordar dos casos distintos tiene como objetivo señalar las diferencias entre una y otra comunidad indígena en el mismo municipio, destacando las respuestas locales y la capacidad de agencia de los actores sociales. Estos dos casos contradicen la vieja idea de que "las sociedades rurales se caracterizan por una homogeneidad social fuertemente contrastante con la heterogeneidad propia de las relaciones urbanas". ${ }^{8}$ En función de ello y como lo advierten Grajales y Concheiro, enfoques teóricos como el de nueva ruralidad "señalan la emergencia de diversas corrientes críticas respecto de las concepciones tradicionales del mundo rural". ${ }^{9}$ Con énfasis en la ruralidad, este trabajo adopta un esquema que no reduce la economía rural a lo agrícola, ${ }^{10}$ en el que el análisis de los cambios "no se limita al ámbito económico, aunque se le da prioridad, sino que también abarca cambios en la sociedad". ${ }^{11}$ Es a partir de dicho marco de análisis que se propone la explicación de las economías nahua y otomí, en el periodo que va de los sesenta a la primera década del nuevo siglo. Cabe señalar que la información original presentada fue obtenida en distintos periodos de trabajo etnográfico, realizados entre el año 2007 y el 2016.

${ }^{8}$ Sergio Grajales Ventura y Luciano Concheiro Bórquez. "Nueva ruralidad y desarrollo territorial. Una perspectiva desde los sujetos sociales”. Veredas (18) (2009): 148.

${ }^{9}$ Ibid., 146.

${ }^{10}$ Cristóbal Kay, "Estudios rurales en América Latina en el periodo de globalización neoliberal: ¿una nueva ruralidad?” Revista Mexicana de Sociología 71(4) (2009): 613.

${ }^{11}$ Idem. 


\section{DE LA COMUNIDAD CAMPESINA CERRADA}

\section{A LA NUEVA RURALIDAD}

Hasta mediados de los años ochenta del siglo anterior, la comunidad como referencia teórica tuvo gran influencia intelectual en los círculos académicos dedicados al estudio de temas sociales en general, y de la antropología mexicana en particular, en su versión indigenista de inspiración culturalista. La comunidad tradicional cerrada, con cambios lentos y apenas perceptibles, fue su unidad de análisis por excelencia. La influencia también se manifestó entre los responsables del diseño y operación de políticas públicas destinadas a remediar el problema de la cuestión indígena. Por entonces se habló mucho acerca de la importancia del "desarrollo de la comunidad" y de "etnodesarrrollo", el bienestar a partir de los recursos propios.

Aguirre Beltrán concluye que la comunidad es vista como una "sociedad sin clases sociales, organizada como un grupo de status, de índole sacra y naturaleza folk" ${ }^{12} \mathrm{El}$ mismo Aguirre Beltrán postula que la indígena no es una "economía de mercado o de dinero, sino que es una economía de subsistencia”, con unidades económicas que sólo producen aquello que requieren. Aclara enseguida que la indígena no es una economía subdesarrollada, sino distinta a la moderna, que puede ser: 1) una economía de subsistencia capaz de sustentar una esfera de prestigio rica o; 2) una economía apenas suficiente para mantener una vida pobre al nivel mínimo de subsistencia. ${ }^{13}$ Sin embargo, la economía indígena se encuentra sometida a la economía ladina.

En las llamadas zonas de refugio, siguiendo al autor, los ladinos residen en la ciudad metrópoli, en nuestro caso en la cabecera municipal (Pahuatlán de Valle), donde controlan las actividades económicas del centro rector. "Las ciudades ladinas son ciudades mercado.

${ }^{12}$ Gonzalo Aguirre Beltrán, Regiones de refugio. El desarrollo de la comunidad y el proceso dominical en mestizoamérica (México: UV, INI, Gobierno del Estado de Veracruz, Fondo de Cultura Económica, 1991), 156.

${ }^{13}$ Ibid., 159. 
El mercado domina a tal punto la vida de la región que le impone su ritmo y normas particulares". ${ }^{14}$

Como indica el teórico Cristóbal Kay: "Las transformaciones que se generaron a partir del proceso de globalización neoliberal impulsaron a los sociólogos rurales a buscar nuevos conceptos que captaran los cambios con mayor claridad". ${ }^{15}$ La noción de nueva ruralidad surge a finales de los años ochenta del siglo xx en América Latina, a la par de otro concepto recurrente en Europa, el de multifuncionalidad. ${ }^{16}$ Se trata de enfoques que resaltan las condiciones y nuevas alternativas de subsistencia económicas de grupos rurales en contextos de globalización. Ambos conceptos se han ido posicionando tanto en los ámbitos académico y gubernamental, como en los de la sociedad civil, destacando que dichos conceptos no sólo refieren a la actividad agrícola, sino a la "totalidad de lo rural". ${ }^{17}$ Hubert C. de Grammont ubica dos vertientes en el estudio de la nueva ruralidad: "el que se centra en las transformaciones económicas, sociales y políticas de la sociedad. Por otro lado, el dedicado a establecer cuáles deben ser las nuevas políticas públicas". ${ }^{18}$

Kay reconoce que si bien "el enfoque de nueva ruralidad tiene ciertamente sus fallas [...] tiene el mérito de haber logrado que mucha gente estuviera consciente de los cambios que anteriormente se habían ignorado, dando pie así a reflexiones adicionales sobre las actuales transformaciones rurales de Latinoamérica [... $]{ }^{\prime 19}$ En esa misma línea de ideas, C. de Grammont agrega que "la importancia relativa de cada fenómeno y el contexto general han cambiado en tal

${ }^{14}$ Ibid., 155.

${ }^{15}$ Kay, "Estudios rurales", 608.

${ }^{16}$ Ibid., 609. Kay señala cómo algunos autores europeos utilizan el término "nueva pluriactividad rural" (Sveinung Eikeland, "New Rural Pluriactivity? Household Strategies and Rural Renewal in Norway", Sociologia Ruralis 39 (3) (1999): 359-376) y abogan porque se dejen de utilizar conceptos como "rural" para que, en su lugar, se estudie lo "postrural” (Jonathan Murdoch y Andy C. Pratt. "Rural Studies: Modernism, Postmodernism and the 'Post-rural". Journal of Rural Studies 9(4) (1993): 411-427).

${ }^{17}$ Grajales y Concheiro, "Nueva ruralidad", 151.

${ }^{18}$ Hubert C. de Grammont, "El concepto de nueva ruralidad", en La nueva ruralidad en América Latina, comp. Edelmira Pérez C., María Adelaida Farah y Hubert C. de Grammont, 26 (Bogotá: ClACso, Pontificia Universidad Javeriana, 2008).

${ }^{19}$ Kay, "Estudios rurales", 633. 
forma que el panorama rural es profundamente diferente porque se han construido nuevos territorios, nuevos actores sociales, nuevas relaciones sociales, en fin, una nueva sociabilidad no solo en el campo mismo sino en su relación con la ciudad" ${ }^{20}$ En efecto, la nueva ruralidad, desde el punto de vista de C. de Grammont, "implica la existencia de cambios pertinentes en el campo que parecen marcar una nueva etapa en su relación con la ciudad y la sociedad en general, tanto en el nivel económico como en el social, cultural y político". ${ }^{21}$

Sin embargo, siguiendo a Kay, el término de nueva ruralidad carece (al menos hasta 2009, cuando fue publicado su artículo) de una definición precisa: "nunca ha sido desarrollado de un modo sistemático y total". ${ }^{22}$ Tal vez, la ambigüedad del término es lo que ha permitido aplicarlo a cualquier tema novedoso o no suficientemente atendido: "quizás, lo nuevo es que ahora se mira una realidad que antes se ignoraba", ${ }^{23} \mathrm{o}$ bien "nos muestra algunas facetas de la realidad social rural que quedan ocultas por los enfoques agraristas", ${ }^{24}$ como señalan los escépticos de la nueva ruralidad. Al respecto, C. de Grammont reconoce que "la expresión nueva ruralidad tiene un significado polisémico que limita su uso conceptual", ${ }^{25}$ mientras que Sergio Gómez indica que "una de las razones que contribuyen a confundir los alcances de la definición de nueva ruralidad es que se tiende a confundir la definición de procesos con la definición de conceptos". ${ }^{26}$ Por mi parte, añadiría que también in-

${ }^{20}$ C. de Grammont, "El concepto de nueva ruralidad", 27.

${ }^{21}$ Ibid., 34.

${ }^{22} \mathrm{Al}$ respecto, Kay (“Estudios rurales”, 610) reconoce las aportaciones de Luis Llambí Insua, "Globalización y nueva ruralidad en América Latina: una agenda teórica de investigación”, ALASRU. Revista Latinoamericana de Sociología Rural (2) (1994): 29-39.

${ }^{23}$ Sergio Gómez E., La "nueva ruralidad": ¿Qué tan nueva? Revisión de la bibliografia, un intento por definir sus limites y una propuesta conceptual para realizar investigaciones (Santiago: Universidad Austral de Chile, 2002), 12. Citado en Kay, "Estudios rurales", 611.

${ }^{24}$ C. de Grammont, "El concepto de nueva ruralidad", 27.

${ }^{25}$ Ibid., 34.

${ }^{26}$ Sergio Gómez, "Nueva ruralidad (fundamentos teóricos y necesidad de avances empíricos)". Documento de trabajo presentado en el Seminario Internacional El Mundo 
fluye la disciplina desde la que se estudia el fenómeno, así como las propias exégesis locales consideradas, aunque es cierto que siempre se corre el riesgo de generalizar a partir de casos aislados. No obstante ese riesgo, si fuera cierto que la mirada de un antropólogo puede aportar elementos omitidos por un sociólogo, un demógrafo o un economista, y si con Gómez se conviene en que "para captar la totalidad y globalidad de la realidad rural [...] será necesario considerar el conjunto de miradas, para lograr una visión comprensiva de la nueva ruralidad", ${ }^{27}$ conviene entonces destacar el punto de vista de los actores sociales.

Como he señalado anteriormente, la finalidad de este artículo es ubicar las especificidades y variaciones entre los casos otomí y nahua, así como reconocer la manera en que éstas influyen en las respuestas locales ante nuevas condiciones de vida. Es cierto que la globalización y la mundialización de la economía permean esas comunidades de la Huasteca poblana. En ese contexto, es importante analizar las circunstancias precisas que motivan respuestas específicas por parte de éstas.

Bajo esta óptica, retomo la noción de mundo rural que propone Baudel Wanderley, como:

un universo socialmente integrado al conjunto de la sociedad [...] y al contexto actual de las relaciones internacionales [...] [sin suponer] la existencia de ningún universo aislado, autónomo en relación al conjunto de la sociedad y que tenga lógicas exclusivas de funcionamiento y reproducción. Pero considero que este mundo rural mantiene particularidades históricas, sociales, culturales y ecológicas, que lo recortan como una realidad propia, de la cual hacen parte, inclusive, las propias formas de inserción en la sociedad que lo engloba. ${ }^{28}$

Rural: Transformaciones y Perspectivas a la Luz de la Nueva Ruralidad, Bogotá, Colombia, octubre 15-17, 2003, 11.

${ }^{27}$ Ibid., 13.

${ }^{28}$ Maria de Nazareth Baudel Wanderley, "A ruralidade no Brasil moderno. Por um pacto social pelo desenvolvimento rural”, en ¿Una nueva ruralidad en América Latina?, comp. Norma Giarracca, 32 (Buenos Aires: CLACSO, ASDI, 2001). 
Para puntualizar, Grajales y Concheiro destacan en la perspectiva de la nueva ruralidad, "el reconocimiento del carácter pluriactivo del mundo rural conduce a replantear aquellas visiones que tomaban a la actividad agrícola como criterio exclusivo en la definición de la ruralidad. Ésta pasa de ser exclusivamente el 'sector agrícola' a descubrirse como 'el mundo rural' productiva y ocupacionalmente diverso". ${ }^{29}$ ¿Cuáles son entonces esas características del contexto rural? ¿Cómo han ido cambiando?

\section{VIEJA RURALIDAD, MISMOS PROBLEMAS}

Como bien señala Patricia Arias, hablar de una nueva rusticidad nos remite a ubicar la vieja ruralidad, la cual se puede entender como "ese largo periodo de la historia mexicana en que se pensó, representó y actuó como si lo único que allí existiera, definiera y organizara las economías rurales fueran las actividades agrícolas de la gente del campo", ${ }^{30}$ es decir, una sinonimia entre la vida rural y el quehacer agrícola, en oposición a la vida urbana y la descampesinización. A propósito de esa ruralidad que permeó durante buena parte del siglo pasado, hay que destacar que se intensificó a partir de la Revolución Mexicana. De ahí que, parafraseando a Arturo Warman, los campesinos se convirtieran en "los hijos predilectos del régimen", ${ }^{31}$ generando una "relación de dependencia y complicidades entre las sociedades rurales y el estado posrevolucionario". ${ }^{32}$ Para Patricia Arias, concebir bajo esta óptica al campesinado tuvo tres grandes consecuencias: diluir la complejidad y variedad de sociedades del país; ${ }^{33}$ ocultar la transición que llevó de una economía de autosufi-

${ }^{29}$ Grajales y Concheiro, “Nueva ruralidad”, 146.

${ }^{30}$ Patricia Arias, "Nueva ruralidad: antropólogos y geógrafos frente al campo hoy", en Lo urbano-rural, ¿nuevas expresiones territoriales?, coord. Héctor Ávila Sánchez, 124 (México: CRIM, Universidad Nacional Autónoma de México, 2005).

${ }^{31}$ Arturo Warman, Ensayos sobre el campesinado en México (México: Nueva Imagen, 1980).

${ }^{32}$ Arias, "Nueva ruralidad", 124.

${ }^{33}$ González et al., identifica tres categorías de campesinos o "gente del campo": indios, rancheros y campesinos. Sus criterios de clasificación giran en torno a la ubicación geográfica, organización social y valores culturales. Creer que el campesino es el mismo 
ciencia y equilibrio, a una de ingresos en efectivo y nuevas prácticas de consumo; por último, impedir la comprensión y justa evaluación del peso creciente de la migración laboral estacional, más allá de la noción de "complementariedad" ${ }^{34}$ Fue desde esa óptica que tanto el sector gubernamental como el gremio académico documentaron y trabajaron con los campesinos del país. "La asociación entre sociedad rural y producción agrícola fue, sobre todo, una construcción social que sirvió para delinear y organizar, durante décadas, la relación entre Estado y los campesinos". ${ }^{35}$

En esa noción de vieja ruralidad se aprecia una clara dicotomía de polos antagónicos y mutuamente excluyentes: o bien se trata de campesinos dedicados a la agricultura y que habitan en contextos rurales; o de obreros y trabajadores del sector industrial en la urbe. Para David Skerritt, esto no es más que una falsa analogía entre "rural y campesino". En su opinión, "lo rural y lo urbano deberían contemplarse como un sólo proceso y no como dos esferas separadas de un binomio" ${ }^{36}$ En este punto es pertinente el cuestionamiento de Luis González sobre cómo contextualizar a las sociedades rurales, siendo que en algunos casos éstas dependen fuertemente del ámbito urbano. ${ }^{37}$ En ese sentido, las propuestas de la nueva ruralidad buscan evitar las dicotomías del tipo tradicional / moderno; rural / urbano; campo / ciudad; agricultura / industria; indígenas, rancheros, campesinos / profesionistas; educación / analfabetismo; religión / laicidad; lealtades primordiales / democracia; usos y costumbres / prácticas “racionales”. Para Hubert C. de Grammont se trata de "una nueva relación 'campo-ciudad' en donde los límites entre ambos ámbitos de la sociedad se desdibujan, sus interconexiones se multiplican, se confunden y se complejizan" ${ }^{38}$

desde tiempo remoto es una distorsión. Luis González y González, Fernán González y Martín González, "Entrevista de Enrique Krauze, 'Gente del campo”. Vuelta (151) (1989): 22.

${ }^{34}$ Arias, "Nueva ruralidad", 125-126.

${ }^{35}$ Ibid., 127.

${ }^{36}$ Skerritt, Campesinos, 8.

${ }^{37}$ González et al. "Gente de campo".

${ }^{38}$ C. de Grammont, "La nueva ruralidad”, 281. 


\section{LA APERTURA Y LA CRISIS}

Desde mediados de la década de 1960, el campo mexicano enfrenta una crisis a consecuencia de la transferencia de recursos de la producción rural al desarrollo industrial. En las dos décadas siguientes, la crisis económica afecta en general a la economía nacional, expresándose en las devaluaciones de la moneda mexicana frente al dólar en 1976 y 1982, así como en los escasos márgenes de ganancia para los campesinos que adquieren insumos a altos costos y deben vender su producción a precios reducidos.

El ingreso de México al Acuerdo General sobre Aranceles Aduaneros y de Comercio (GATT, por sus siglas en inglés: General Agreement on Tariffs and Trade) en 1986, y al Tratado de Libre Comercio (TLC) en 1994, merman considerablemente los apoyos gubernamentales para la agricultura, los cuales se dan a través de créditos, asesoría técnica y apoyos a la comercialización. Como lo señalan distintos autores, entre ellos Rubio, Aragonés y Appendini, ${ }^{39}$ el proyecto neoliberal aplicado en México a partir del sexenio del presidente $\mathrm{Mi}$ guel de la Madrid (1982-1988) comienza la transformación general de la economía nacional, así como las alternativas de vida de las poblaciones rurales y urbanas. Este proyecto, que se inscribe en una etapa de globalización del capital, afecta negativamente a la fuerza de trabajo de las comunidades rurales. Ante ello, una de las respuestas que la gente encuentra es la movilidad geográfica a distintos lugares, entre ellos zonas urbanas, en busca de mejores condiciones de trabajo. Las transformaciones en el mundo social que rodea al campo, así como los cambios en el nivel de la producción agraria, pivo-

${ }^{39}$ Blanca Rubio, "El sector agropecuario mexicano en los años noventa: subordinación desestructurante y nueva fase productiva", en El sector agropecuario mexicano frente al nuevo milenio, coord. Blanca Rubio, 17-45 (México: IIs, Universidad Nacional Autónoma de México, Plaza y Valdés, 2004); Ana María Aragonés, "Migración y explotación de la fuerza de trabajo en los años noventa: saldos del neoliberalismo", en El sector agropecuario mexicano frente al nuevo milenio, coord. Blanca Rubio, 239-268 (México: IIs, Universiad Nacional Autónoma de México, Plaza y Valdés, 2004); Kirsten Appendini, "La transformación de la vida rural en tres ejidos de México", en ¿Ruralidad sin agricultura? Perspectivas multidisciplinarias de una realidad fragmentada, ed. Kirsten Appendini y Gabriela Torres-Mazuera, 27-57 (México: El Colegio de México, 2008). 
teados por poderosos actores económicos, resultan en esas nuevas configuraciones que los sociólogos latinoamericanos conceptualizan a la postre como nueva ruralidad. ${ }^{40}$

Si en la década de los sesenta la actividad agrícola todavía permite la reproducción de las unidades de producción familiar de muchas zonas rurales del país, esta realidad cambia notablemente hacia finales de los ochenta y las dos décadas siguientes. Al respecto, C. de Grammont menciona que hasta finales de los sesenta el sector agropecuario en México funciona como palanca de acumulación para facilitar el despegue del sector industrial nacional. ${ }^{41}$ Pero ese periodo del "milagro mexicano" dejó de ser tal en los ochenta. Arias confirma dos de las principales características del campo mexicano en esa década: 1) la crisis de la economía nacional que lleva a la reducción de los apoyos para el campo; y 2) el ingreso al GATT en 1986 y al TLC en $1994 .^{42}$

$\mathrm{Al}$ respecto, Aragonés explica el impacto negativo que el TLC tuvo en la economía mexicana y en específico en las zonas rurales: "las políticas relacionadas con la apertura comercial impidieron fortalecer el mercado interno y los sectores productivos se vieron sobrepasados por la competencia internacional". ${ }^{43}$ Para el campo, el TLC, lejos de ser el inicio de un nuevo proceso, debe verse como la última fase de un largo proceso de transformación. ${ }^{44} \mathrm{~A}$ partir de las reformas que trajo consigo la producción agrícola del país sufrió una disminución notable, pasó de 4.24 millones de toneladas en el periodo de 1989-1993 a 2.28 millones de toneladas para el periodo de 1994-1999.

Aunado al proceso de modernización de la región que me ocupa, hay que destacar que si en las décadas de los sesenta y setenta la acti-

${ }^{40}$ Norma Giarracca y Bettina Levy, "Introducción. América Latina, nuevas ruralidades, viejas y nuevas acciones colectivas", en Ruralidades latinoamericanas. Identidades y luchas sociales, comp. Norma Giarracca y Bettina Levy, 13-39. Buenos Aires: CLAcso, 2004.

${ }^{41}$ C. de Grammont, "La nueva ruralidad".

${ }^{42}$ Arias, "Nueva ruralidad".

${ }^{43}$ Aragonés, "Migración y explotación”, 247.

${ }^{44}$ Hubert C. de Grammont y Héctor Tejera, coords., La sociedad rural mexicana frente al nuevo milenio (México: Plaza y Valdés, UAM, Universidad Nacional Autónoma de México, Instituto Nacional de Antropología e Historia, 1996). 
vidad agrícola todavía es la base de la reproducción de la unidad familiar, ésta cambió notablemente hacia finales de los ochenta y las dos décadas siguientes, pues, la actividad agrícola en el país se insertó en un esquema mundial y surgieron nuevos estándares de calidad y de exigencias en la competitividad para las empresas. A partir de las reformas del TLC, la producción nacional de granos y otros alimentos se queda sin comercializar debido a las grandes diferencias en los precios respecto de los granos adquiridos en el exterior. Lo mismo ocurre con el sector ganadero en otras latitudes de la Huasteca, pues, con el ingreso de México al GATT se eliminaron la mayoría de los aranceles y se facilitó la importación de carne al país. Como consecuencia de todo ello, Aragonés puntualiza que, al despuntar el tercer milenio, "uno de cada seis mexicanos abandonaron sus tierras, y se han concentrado en las ciudades del centro y norte del país, o bien, emigraron a Estados Unidos en busca de un empleo redituable". ${ }^{45}$

Al "fenómeno" de la nueva ruralidad, Giarracca y Levy adicionan otros elementos, ampliando la perspectiva de su estudio: el incremento de las migraciones, el incremento de la densidad poblacional en las comunidades y pueblos (el fenómeno de la "rururbanización”), y la importancia de los territorios y localidades en la articulación de las estrategias familiares, de las nuevas protestas y movimientos sociales. ${ }^{46}$ En efecto, la migración del campo es un fenómeno que se explica, en parte, por la persistencia de una política deliberada de los gobiernos neoliberales, que en los hechos empobrece a la población campesina y la empuja a migrar a las grandes ciudades, incluso fuera de México, para no tener que procurar condiciones de subsistencia dignas en los entornos rurales.

Entre otras, ésas son algunas de las razones por las cuales la crisis económica en el agro mexicano se agudizó en la década de los ochenta, propiciando un cúmulo de dificultades para los agricultores que subsistían del cultivo y comercialización de su producción agrícola. Así ocurrió entre los campesinos de diferentes pueblos de la

${ }^{45}$ Aragonés, “Migración y explotación”, 248.

${ }^{46}$ Giarracca y Levy, "Introducción. América Latina”. 
Huasteca y otras regiones del país. En esas regiones, el descenso del comercio agrícola fue uno de los detonantes para que los habitantes de las comunidades buscaran nuevas opciones laborales fuera de sus comunidades. Tales fueron los casos de los otomíes, nahuas y mestizos de Pahuatlán, de los que abundaré en los primeros dos.

\section{OTOMÍES Y NAHUAS: EL DILEMA DE LA SUBSISTENCIA}

La sierra norte de Puebla, cuyas dos porciones corresponden una a la Huasteca sur y otra al Totonacapan, se distingue por ser un espacio y un territorio diverso en donde cohabitan varios grupos étnicos -otomíes, nahuas, totonacos, tepehuas, mestizos y afromestizos-. La adscripción a una u otra región obedece a criterios geográficos, pero principalmente culturales e históricos. En el municipio de Pahuatlán, mestizos e indígenas se autoadscriben y se reconocen como huastecos. ${ }^{47}$ No es extraño escuchar que los lugareños señalen que parte de la Huasteca poblana también se ubica en aquellas zonas de mayor atracción laboral en los Estados Unidos de América, pues, los vínculos, prácticas, historias biográficas y familiares, rebasan los límites geográfico-administrativos. Desde esta perspectiva, partimos de la idea de que las regiones son constructos culturales, los cuales se van redefiniendo a partir de los actores sociales.

En términos administrativos, el municipio de Pahuatlán forma parte de la región socioeconómica número 1 del estado de Puebla y del distrito electoral-judicial con cabecera en Huauchinango. El municipio de Pahuatlán colinda con los municipios poblanos de Honey, Naupan y Tlacuilotepec, así como con los hidalguenses de Acaxochitlán y Tenango de Doria. Pahuatlán está conformado por población originaria de habla otomí y nahua, así como por mestizos que llegaron a establecerse en la cabecera municipal a finales del siglo XVII. ${ }^{48}$

${ }^{47}$ Libertad Mora Martínez, "Dinámicas migratorias en Pahuatlán: municipio de indígenas y mestizos en la Sierra Norte de Puebla (1980-2010)" (Tesis de maestría en Antropología Social, Ciesas Golfo, 2011).

${ }^{48}$ José de Jesús Montoya Briones, Atla. Etnografía de un pueblo náhuatl (México: Instituto Nacional de Antropología e Historia, 1964). 
El conteo realizado por el INEGI en 2015 arroja una población total para el municipio de 22,002 personas. Con información más detallada, el censo de 2010 ofrece la cifra de 20,618 habitantes, de los cuales 11,531 habitan en hogares indígenas, de entre los cuales 9,927 tienen 3 ańos o más y son hablantes de lengua indígena. Según el Sistema Nacional de Indicadores elaborado por la CDI con base en el mismo censo de 2010 del INEGI, el municipio de Pahuatlán tendría una población indígena de 11,616 personas, de las cuales 6,817 son nahuas y 4,701 otomíes. La población nahua se concentra en las comunidades de Xolotla, Atla, Mamiquetla y Atlaltongo, mientras que la otomí en San Pablito, Xochimilco y Zacapehuaya. Estos últimos, los hñähñü -como se identifican- u otomíes de Pahuatlán, representan la mayor concentración de población otomí que habita en el estado de Puebla. De esas comunidades, como he indicado, este artículo se concentra en dos. Por un lado Xolotla, conformada según el censo de 2010 por 654 hogares con un total de 2,770 habitantes, de los que 2,370 tienen tres años o más y la mayoría de ellos habla lengua náhuatl; por otro, San Pablito, comunidad de la que forman parte las localidades de Agua del Carrizo, Agua Negra, Agua del Machete e incluso otra localidad igualmente llamada San Pablito, censadas por el INEGI como localidades distintas en 2010. La comunidad de San Pablito, nombrada Mbithö en otomí, contabiliza en sus cinco localidades 809 hogares con un total de 3,646 habitantes, de los cuales 3,307 tienen tres años o más y hablan, casi todos ellos, lengua otomí. ${ }^{49}$

Pahuatlán de Valle, como se llama oficialmente la cabecera municipal de Pahuatlán, ha servido como un punto de comunicación entre las sierras poblana, hidalguense y veracruzana; así como entre el Altiplano y las llanuras del Golfo de México. Desde el pasado colonial, el comercio de productos agrícolas ha jugado un papel de

\footnotetext{
${ }^{49}$ San Pablito, localidad: 693 hogares; 3,178, habitantes; 2,890 hablantes de lengua indígena de 3 o más años. Agua del Carrizo: 7 hogares; 22 habitantes; 21 hablantes de lengua indígena de 3 años o más. Agua Negra: 31 hogares; 126 habitantes; 116 hablantes de lengua indígena de 3 años o más. Agua del Machete: 70 hogares; 292 habitantes; 260 hablantes de lengua indígena de 3 años o más. San Pablito (?), segunda localidad homónima: 8 hogares; 28 habitantes; 20 hablantes de lengua indígena de 3 años o más.
} 


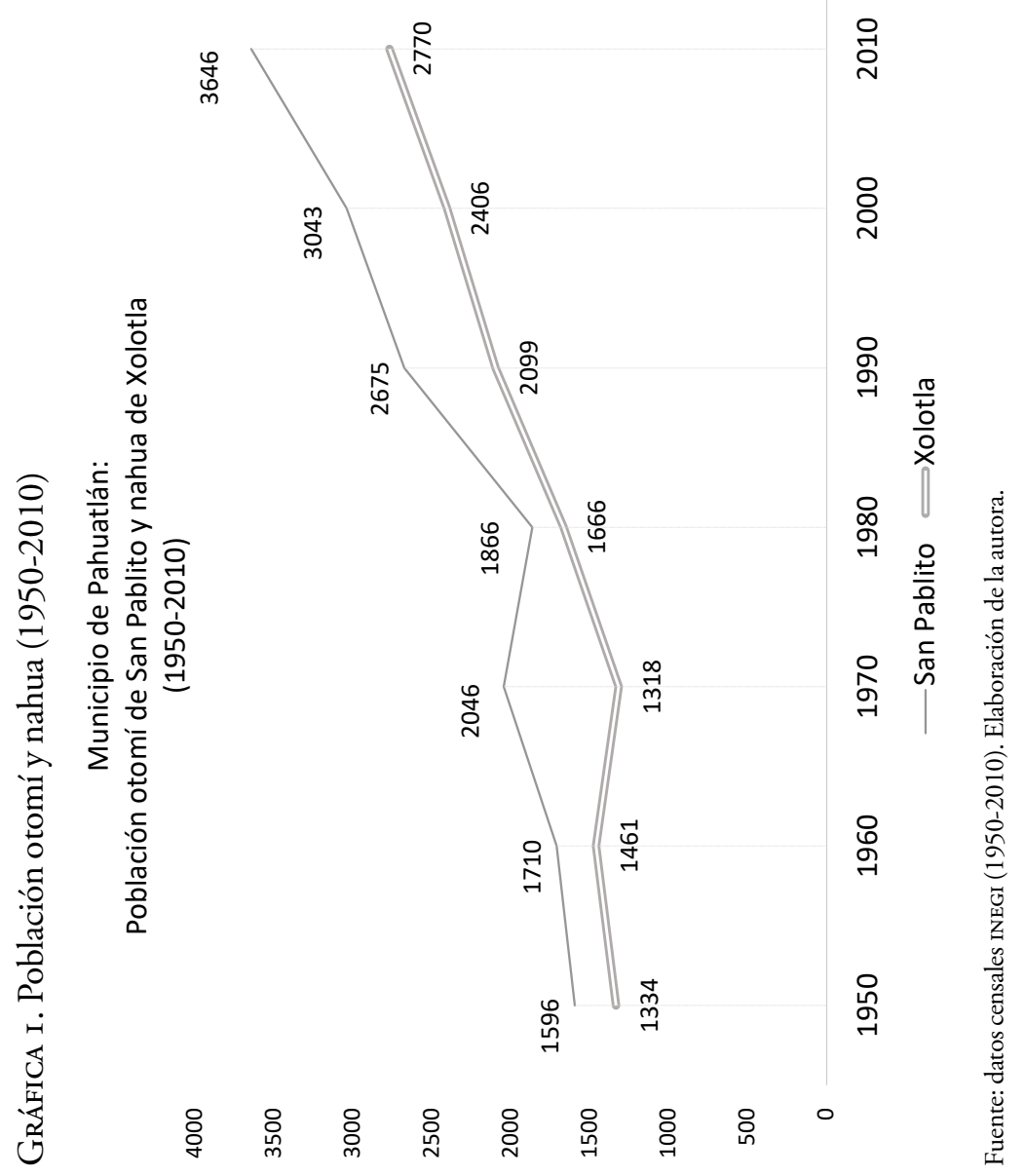


importancia en la economía del antiguo pueblo de Pahuatlán. ${ }^{50} \mathrm{La}$ inauguración en 1908 de un ramal del ferrocarril que tuvo por estación terminal al vecino pueblo de Chila -hoy Honey (Puebla)- benefició notablemente el comercio agrícola y la economía en la zona, además de propiciar y reforzar lazos entre los pueblos del Golfo con los del Altiplano. En ese entonces, y probablemente desde épocas anteriores, los pueblos serranos como Pahuatlán servían de enlace entre la ciudad de México y la Huasteca, especialmente, con las porciones veracruzana e hidalguense, con las que mantenía vínculos comerciales a través de la arriería, ya que hasta antes de la década de los sesenta no existían carreteras ni caminos aptos para el tráfico vehicular. Los caminos que existían eran de herradura, antiguos caminos reales, así que quienes decidían salir del pueblo lo hacían a lomo de bestias, o caminando, atravesando veredas.

Ahondando en lo anterior, Bravo describe la ruta comercial de los arrieros a la Huasteca, indicando que ésta "partía de Tulancingo a Pahuatlán, llegando hasta Metlaltoyuca y de allí a Huejutla”. ${ }^{51} \mathrm{Y}$ en efecto, en Pahuatlán se daban cita arrieros de distintas partes de la Huasteca. Si bien, la arriería fue principalmente "oficio de mestizos pobres" de las cabeceras municipales, ${ }^{52}$ en Pahuatlán también hubo arrieros de las comunidades indígenas, en específico, nahuas del pueblo de Xolotla. Los lugareńos argumentan que una de las ventajas de estos arrieros era que el comercio lo realizaban, bien en castellano o bien en lengua indígena, facilitando las ventas y ampliando rutas comerciales, multiplicando amistades, extendiendo redes de compadrazgo y hasta sumando nuevas relaciones extramaritales que en su camino iban consiguiendo. Con los otomíes de San Pablito ocurrió algo distinto. Participaban de una serie de vínculos

${ }^{50}$ Bernardo García Martínez, Los pueblos de la sierra: el poder y el espacio entre los indios del norte de Puebla hasta 1700 (México: El Colegio de México, 1987); Guy StresserPéan, Los lienzos de Acaxochitlán (Hidalgo) y su importancia en la historia del poblamiento de la Sierra Norte de Puebla y zonas vecinas, trad. Araceli Méndez y Angelines Torres (México: IHemsys, CECA, Gobierno del Estado de Hidalgo, CEMCA, 1998).

${ }^{51}$ Carlos Bravo Marentes, Arrieros somos: el sistema de arriería de la Sierra Norte de Puebla (México: DGCP, Conaculta, 1988), 8.

${ }^{52}$ Ibid., 7. 
comerciales con otomíes de otras comunidades de la región, pero ellos no salieron a "ranchear" productos, sino que compraban y vendían a los arrieros y a los "santaneros" (otomíes nativos de Santa Ana Hueytlalpan, municipio Tulancingo, Hidalgo) que recorrían el oriente de la Huasteca hidalguense, el sur de la Huasteca veracruzana y el extremo norte de la Huasteca poblana.

Pero tal como seńala Velázquez, ${ }^{53}$ a partir de la década de los sesenta la arriería empieza a perder importancia inmediatamente después de la construcción de las carreteras México-Tuxpan y Veracruz-Poza Rica, de manera que conforme se construyen nuevos caminos para carros y camiones, la arriería se circunscribe cada vez más limitadamente al interior de la sierra poblana. Ya entrados los años ochenta, la construcción de la carretera interserrana prácticamente da por terminada la actividad de la arriería, oficio que, como señala Bravo, había sido pero dejó de ser "la actividad económica por excelencia que no sólo brindaba beneficios económicos, sino gran prestigio social". ${ }^{54}$ Chamoux confirma que "de esas familias de comerciantes y arrieros habían salido los jefes militares y políticos de la región durante el siglo XIX, así como, posteriormente, los caciques de la primera mitad del siglo xx" ${ }^{55}$ En ese tenor, acota que la arriería también fue un oficio que generó algún tipo de capital social entre grupos indígenas de la región, por ejemplo, a partir de las relaciones que se establecieron entre nahuas de Pahuatlán con aquéllos de Acaxochitlán (Hidalgo), Naupan y Huauchinango (Puebla); así como entre otomíes pahuatecos con otros otomíes de Tenango de Doria y Tulancingo (Hidalgo). En campo he podido constatar que esos vínculos del pasado se han ido actualizando en el presente, generando una serie de alianzas y redes entre grupos de la misma filiación étnica.

${ }^{53}$ Emilia Velázquez Hernández, Cuando los arrieros perdieron su camino. La conformación regional del Totonacapan (Zamora: El Colegio de Michoacán, 1995).

${ }^{54}$ Bravo, Arrieros somos, 7.

${ }^{55}$ Marie-Noëlle Chamoux, Nahuas de Huauchinango: transformaciones sociales en una comunidad campesina, trad. Luz María Santamaría (México: INI, CEMCA, México, 1987), 40, 46. 


\section{CAÑA DE AZÚCAR Y OTROS CULTIVOS}

SOBREVIVIENTES (I960-20IO)

Como en otras comunidades de la sierra del norte de Puebla, durante la segunda mitad del pasado siglo $\mathrm{xx}$, las familias de las comunidades indígenas y mestizas de Pahuatlán se dedicaron principalmente a actividades agrarias, destinando la mayor parte de su producción al autoconsumo y una menor cantidad (el excedente) al comercio local o regional. Como he señalado antes, la arriería y el ferrocarril sirvieron para que otomíes, nahuas y mestizos comercializaran sus cosechas que eran llevadas fuera de la región. Como en otras regiones mesoamericanas, la producción destinada al autoconsumo tenía por pilares principales los de la milpa, con el maíz por delante.

En comunidades mestizas como Acalapa, Linda Vista, Tlalcruz de Libres, Ahuacatitla y Xilepa, se cultivaban cítricos, tomates, pahuas (una variedad del aguacate), "espinosos" (un tipo de chayote) y garbanzos. En Paciotla las familias se dedicaron, desde entonces y hasta la fecha, a la apicultura. Hubo también algunos negocios de plantas y hierbas medicinales que se cultivaban y se comercializaban en distintas partes del país. En el año 2010 sólo un par de familias mestizas se dedican a ese negocio.

Por cuanto a los cultivos agrícolas de la población indígena se observa algo distinto, pues, si bien los terrenos de los nahuas y otomíes no están volcados al monocultivo, ocurre que en el curso de las últimas cuatro décadas (1970-2010) se han enfocado temporalmente en ciertos cultivos específicos. Así, entre los otomíes de Zacapehuaya y Chila, el zapote ha representado un producto importante para la manutención de las unidades domésticas. En el caso de Xochimilco y San Pablito, en los sesenta figuraban los cultivos de maíz, chile, tomate, café, caña de azúcar, piña, maíz, garbanzo, cacahuate, entre otros. Entre los sanpableños, el maíz tuvo un lugar importante en un primer momento, pero cedió su lugar como producto comercializable frente a la caña de azúcar y al chile, enseguida al café y, más recientemente, al cacahuate, este último actualmente sigue vigente en la producción y comercio local, aunque el café y el cacahuate no tuvieron ni tienen una importancia económica gene- 
ralizada en la comunidad. Si bien, hay algunas familias sanpableñas que en sus pequeñas huertas aún siembran maíz, café y chile, sólo lo hacen para el consumo doméstico. De hecho, la mayoría compra maíz, también sus vecinos hñähñü de Tenango de Doria (Hidalgo).

Por su parte, a principios de los sesenta, los nahuas de Atla (municipio Pahuatlán, Puebla) cultivaban principalmente caña de azúcar, maíz, garbanzo y frijol. ${ }^{56}$ Algo similar sucedía con sus vecinos de Xolotla, pero, a diferencia de aquéllos, a partir de los setenta y hasta la fecha, los nahuas de Xolotla, como mostraré en el siguiente apartado, se han dedicado e incluso especializado en la cafeticultura, abandonando otros cultivos comerciales como el frijol o la cańa de azúcar. Este último cultivo figuró por su importancia comercial tanto entre nahuas y otomíes como entre mestizos. Sin embargo, también padeció la crisis de la agricultura mexicana, pues, parafraseando a C. de Grammont el café y la caña de azúcar fueron los grandes perdedores en la crisis agrícola de los ochenta. ${ }^{57}$

Con la caña de azúcar se elabora el endulzante natural conocido como panela o piloncillo, así como el aguardiente o refino, bebida embriagante de gran demanda en la región. ${ }^{58}$ En el municipio de Pahuatlán, las familias que contaban con pequeños cañaverales, solían procesar la cańa en su misma localidad mediante rudimentarios trapiches de madera, movidos por bueyes, caballos, o en ocasiones por tracción humana. A diferencia del café y otros cultivos locales, la siembra de la caña no es combinable con otras labores, lo cual disminuye su potencial tratándose de economías campesinas tradicionales, en las que la diversificación productiva favorece la seguridad en la producción y reproducción del grupo doméstico. El procesamiento de la cańa requiere, respecto de otros cultivos, de mayor inversión de mano de obra. De hecho, una parte de dicha mano de obra requiere de conocimientos especializados en la elaboración de piloncillo y el manejo de las calderas.

${ }^{56}$ Montoya, Atla, 46.

${ }^{57}$ C. de Grammont, "La nueva ruralidad".

${ }^{58}$ Las bebidas embriagantes de importancia local fueron el aguardiente elaborado en el municipio y sus alrededores, y el pulque producido en los municipios vecinos del Altiplano. 
Los pahuatecos detallan que todavía en los ochenta varias familias mestizas de los barrios de la cabecera municipal, así como nahuas y otomíes, se dedicaban a la elaboración de aguardiente. La producción de alcohol representaba un ingreso económico importante para las unidades domésticas. Los testimonios nahuas y otomíes destacan por igual la importancia que el consumo del destilado tuvo cotidianamente y en ocasiones festivas. Durante años, el éxito de la cańa estuvo en función del consumo de aguardiente. Los dueńos de alambiques, en manos de mestizos, requerían del piloncillo y la leña que compraban a los indígenas.

Hoy se mantiene algo de ello, con la salvedad de que ahora ya muy pocos se dedican a la producción y la transformación de la cańa y, por supuesto, ya no tiene la importancia económica que tuvo en el pasado. El motivo de su abandono, en todo el municipio y prácticamente en toda la región, se explica por el descenso en el precio del azúcar, lo que afectó notablemente la venta de la cańa con la que se fabrica. En efecto, a finales de los setenta, el comercio de café adquirió mayor relevancia en varias partes de la sierra norte de Puebla y sustituyó en importancia a la caña de azúcar. Velázquez opina que esto se debió a dos factores: por un lado, el consumo de azúcar refinada que fue sustituyendo al piloncillo que se fabricaba en la Huasteca y el Totonacapan poblanos; por otro, la clausura, por parte de las autoridades estatales y federales, de las fábricas clandestinas de aguardiente que habían sido fuente de riqueza y poder para caciques locales y regionales. ${ }^{59}$ La destilación de refino que por años tuvo un mercado prácticamente cautivo en la región, de pronto se rompió ante la presencia de bebidas embriagantes embotelladas, de fácil transporte y con un mercado mucho más amplio.

A pesar de ello, en la actualidad aún subsisten algunas fábricas y expendios de aguardiente en las inmediaciones de Honey (Puebla) y Acaxochitlán (Hidalgo). Asimismo, en la cabecera municipal de Pahuatlán de Valle, para los mestizos preservar la tradición de elabo-

${ }^{59}$ Velázquez, Cuando los arrieros, 89; Luisa Paré, “Caciquismo y estructura de poder en la Sierra Norte de Puebla”, en Caciquismo y poder político en el México rural, Roger Bartra, Eckart Boege, Pilar Calvo, Jorge Gutiérrez, Víctor Raúl Martínez Vázquez, Luisa Paré, 31-61 (México: Siglo XXI, 1976). Citado en Ibid. 
rar panela se convirtió en un atractivo turístico. A pesar de esas pervivencias, en estos tres últimos casos la producción y transformación de cańa de azúcar ha sufrido una paulatina pero constante y al parecer irremediable caída.

\section{EL ORO NEGRO}

Poco a poco el café fue haciendo las veces de la caña en la economía familiar, hasta que, hacia el segundo lustro de la década de 1980, prácticamente la desplazó de los pequeños predios, entre otras razones porque, a diferencia del café, la cańa no contó con un mecanismo de intervención estatal que la promoviera con financiamiento, orientación, tecnificación y mercado. Por lo menos no en Pahuatlán.

El café no requiere de gran inversión de fuerza de trabajo. Generalmente, el propietario de la parcela comienza sembrando los cafetos en su barbecho, sin más tecnología agrícola que la antigua coa prehispánica (ahora de fierro), hasta su etapa de producción. Se procura que la plantación sea en espacios cercanos a los árboles altos que dan sombra. Para producir con una orientación hacia el mercado, en cambio, se requiere de nuevos insumos como bombas de aspersión y fungicidas para combatir las plagas.

En el caso del municipio de Pahuatlán se ignora cómo llegaron los primeros cafetos, pero todo hace suponer que el proceso ocurrió paralelo a la introducción del cultivo a mediados del siglo xix en la zona de Teziutlán (Puebla). ${ }^{60}$ De las faldas de Teziutlán se habría desplazado sobre toda la sierra norte de Puebla, mediante los circuitos abiertos por los arrieros. En el origen de la siembra de café tiene un papel relevante la presencia de familias de la comunidad que son propietarias de tierra. Esas familias iniciaron la siembra en sus parcelas de manera "lírica", como suelen decir los productores para referirse a su inexperiencia técnica. Se trataba de producción orientada al autoconsumo, pues el café se incorporó muy pronto a la dieta del pobre. Hasta mediados de los ochenta del siglo pasado, en nuestra

${ }^{60}$ Arturo León López y Cristina Steffen, Ganadería y granos básicos en la Sierra Norte de Puebla: una lucha desigual (México: UAM Xochimilco, 1987). 
zona de estudio, lo que llamaban huertas eran unas cuantas matas escuálidas de café sembradas en los solares, o en los pequeños predios, mezcladas con otro tipo de cultivos. Ninguno de los propietarios cultivaba con fines que no fueran el consumo familiar, y ocasionalmente llevar algunos "cuartillos" al mercado de la cabecera municipal el día de "plaza”. Esa práctica se repetía con el eventual excedente de maíz y frijol, en caso de tenerlo (pues se sabe que la producción campesina está sujeta a muchas contingencias); con el cultivo de algunas hortalizas, la naranja, guayaba, mamey, plátano, zapote, chile, tomate, jitomate y cacahuate. Este género de cultivos, y por su labor tradicional, están sujetos a los ciclos agrícolas, generalmente anuales. Así es que su eventual eficiencia no está determinada por la capacidad del productor, sino por las condiciones del temporal.

La sustitución de la caña de azúcar por el café, que hacia fines de los ochenta se registró entre los nahuas de Xolotla y otomíes de San Pablito, se observó también en otras latitudes de la Huasteca y en el Totonacapan. ${ }^{61}$ La relevancia de la producción cafetalera es de tal tamańo, que el estado de Puebla ocupa el cuarto lugar nacional en producción, ${ }^{62}$ aunque la intensidad varía entre la producción tradicional y los altos niveles de productividad y tecnificación. Sobresalen por su calidad y volumen de producción los productores bien organizados de Cuetzalan del Progreso y Huitzilan de Serdán, en el Totonacapan poblano, así como las grandes fincas de Zihuateutla y Xicotepec, en la Huasteca poblana. Aunque la producción del municipio de Pahuatlán no alcanza las cifras que registran aquellos municipios, ciertamente ocupa un nicho en el mercado del aromático,

${ }^{61}$ Este tema que ha sido documentado por varios autores que han enfatizado la importancia que para indígenas y mestizos tuvo producción y comercialización del café (Arias, "Nueva ruralidad"; Cora Govers, Performing the community: Representation, ritual and reciprocity in the Totonac Highlands of Mexico (Münster: LIT VERLAG Berlin, 2006); Elio Masferrer Kan, Los dueños del tiempo. Los tutunakú de la Sierra Norte de Puebla (México: Fundación Juan Rulfo, 2009); Velázquez, Cuando los arrieros.

${ }^{62}$ Cristina Martínez señala que en Veracruz, Chiapas, Puebla y Oaxaca se concentra $89.02 \%$ del total de los beneficios del país (90.56 \% húmedos y $82.16 \%$ secos). Cristina Martínez, "Transformación de la actividad cafetalera en los años noventa”, en Elsector agropecuario mexicano frente al nuevo milenio, coord. Blanca Rubio, 109-146 (México: IIS, UNAM, Plaza y Valdés, 2004), 111. 
con la participación de pequeños productores que son, a su vez, pequeños propietarios de predios no mayores a cinco hectáreas. En efecto, pese a los grandes cambios en cuestiones agrícolas, el pequeño propietario sigue siendo el tipo de productor predominante en toda la sierra norte de Puebla. ${ }^{63}$ Tanto en Xolotla como en San Pablito, la tierra es propiedad privada, con extensiones que van de una a cinco hectáreas. La media local son dos hectáreas. Se trata del llamado minifundio, producto del acelerado proceso de fragmentación parcelario, motivado por la entrega en herencia de la tierra de una generación a otra, y por la presión demográfica. Como en el siglo XIX, en Pahuatlán la tierra no se vende; se hereda.

El Instituto Mexicano del Café (InMeCAFÉ) fue una agencia federal, creada por el gobierno mexicano en 1958 para intervenir en el sector cafetalero, con el fin de mejorar el cultivo, proceso y comercialización del grano a gran escala. Su mayor auge lo tuvo a partir de 1973, y gozó de éste hasta el ańo de 1989, cuando se le desaparece, envuelto en un mar de acusaciones de corrupción oficial, pero, sobre todo, con el fin de dejar la producción en manos de los monopolios privados. Además de los severos señalamientos de corrupción gubernamental, su desaparición se da a la par con la caída de los precios internacionales del grano y una helada a finales de ese año de 1989, éste meteoro afectó gravemente a cafeticultores de Veracruz, San Luis Potosí y Puebla. Su presencia y accionar en la región fue breve: de apenas cuatro ańos. Sin embargo, en ese periodo, y no obstante la presencia abrumadora de sus promotores, no se observaron cambios económicos entre los productores. La población mantuvo su ritmo de vida sin manifestar mejoras, ni en sus casas ni en su forma de vida, como prometieron que ocurriría si se dedicaban a la producción de lo que llamaban el "oro negro".

En el ańo de 1986 aparecieron los primeros promotores de la "prosperidad y el progreso" a través del señalado Instituto, cuyas oficinas regionales se establecieron en la pequeña ciudad de Xicotepec de Juárez. El nuevo organismo le dio un impulso inusitado a la producción. Por primera vez, los campesinos conocieron de especies

${ }^{63}$ Velázquez, Cuando los arrieros, 57. 
mejoradas, o eso les hicieron sentir. Recibieron capacitación técnica sobre cultivos, financiamiento a un costo razonable y el ofrecimiento de mercado y un pago justo por el producto. Privaban entonces los precios de garantía. Incluso los productores gozaron de la prerrogativa de que, una vez hecha la transacción comercial y el pago, podían reclamar el reembolso en caso de que el precio se incrementara en el curso del año.

La figura organizativa fue la llamada "unidad económica de producción y comercialización” (UEPC). Los cafeticultores recibían crédito para insumos y, ante los ejecutivos de INMECAFÉ, hacían el compromiso de entregar parte de la cosecha correspondiente a la deuda contraída más intereses. El resto de la producción podían utilizarla según quisieran.

La primera distinción en lo tocante a la producción agrícola, ya sean cultivos tradicionales o introducidos, para consumo o para el mercado, es el acceso a la tierra. Para hacerse acreedor a los beneficios de los UEPC, se requería de parcela, ya fuera como propietario o como arrendatario, aunque este segundo no privaba debido al costo adicional que para la producción supone la renta de la tierra. Luego entonces la cafeticultura fue y sigue siendo una actividad constreñida fundamentalmente al sector de los propietarios.

Tanto San Pablito como Xolotla se encuentran por arriba de los 1,100 msnm, esta condición las coloca a una altitud óptima para producir café de buena calidad. De hecho, varias empresas, nacionales o transnacionales (como Nestlé), lo buscan con el fin de mezclarlo con otros de menor calidad y elevarlos.

Ante la persuasión de los promotores de inmeCafé, Manuel Abraham Hernández, sanpableño respetado por sus vecinos y propietario de una hectárea de tierra, determinó en 1986 abandonar la antigua labranza de cańa e introducir el nuevo cultivo que, le dijeron, lo sacaría del "atraso". Otros otomíes de San Pablito siguieron su ejemplo.

Hacia el mismo tiempo, los técnicos de INMECAFÉ obsequiaron a sus "clientes" nahuas de Xolotla un par de despulpadoras y bombas de aspersión: la primera tecnificación. Sin embargo, la producción y proceso de secado, despulpado y molido siempre ha tenido un ca- 
rácter doméstico y familiar. El secado lo hacen en el patio o en la azotea; el despulpado y molido mediante molinos manuales; el tostado, en comal tradicional.

Paralelamente al cultivo de café y su intensificación en algunas comunidades del municipio, se fue consolidando en la cabecera un grupo de personas dedicadas a su compra: los comerciantes mestizos abarroteros, quienes habían levantado fortunas relativas al amparo de la población indígena, mediante el establecimiento de relaciones desiguales de intercambio comercial. Ese mismo esquema se estableció en lo tocante al nuevo cultivo.

De entre el grupo de compradores de café de la cabecera nació coscAFÉ. La encabezó un japonés de apellido Fujigaki, quien hacia los veinte habría llegado al municipio huyendo de la guerra en su país. Al poco tiempo, la suya se consolidó como la más importante comercializadora no sólo en el municipio sino en la región. Fue la primera que estableció un beneficio de café con tecnología de punta. Posteriormente abrió centros de acopio en las ciudades próximas de Tulancingo (Hidalgo) y Xicotepec de Juárez (Puebla). Hoy, coscafé es una de las empresas comercializadoras del grano más importantes en México, que incluso cotiza en la bolsa de valores, y que con el paso de los años ha derivado en un consorcio que cuenta con cadenas de cafeterías que comercializan artículos para cafeterías y restaurantes.

La mejora se manifestó, y mucho, en los mentados "compradores acaparadores" de la cabecera municipal, quienes buscaron las maneras y al parecer las encontraron, mediante sobornos, para que el INMECAFÉ, violando sus propios estatutos, comprara a los intermediarios e incluso para tener acceso a información privilegiada, relativa a las eventuales fluctuaciones del precio. ${ }^{64}$ Como he dicho, la corrupción institucional, los intereses del capital en el contexto internacional y la coyuntura nacional sentenciaron el derrumbe del INMECAFÉ a fines de 1989.

A finales de los noventa se conformó en Xolotla una cooperativa con la intención de buscar apoyos y asesorías gubernamentales para

${ }^{64}$ Son parte de las versiones que se cuentan sobre el paso de la paraestatal en el municipio. 
una mejor comercialización de su producto. Entrado el nuevo milenio, varias instituciones federales encabezadas por el antiguo INI hoy CDI- y la SAGARPA, establecieron en Xolotla un "beneficio de café" con la finalidad de favorecer la producción local. La comunidad fue dotada con todos los recursos tecnológicos, en un predio extenso, con los suficientes espacios para la atención de cada uno de los procesos a los que el grano debe ser sometido para su mejora. Según cálculos de los socios y con estimaciones al año 2000, la inversión en maquinaria fue superior al millón de pesos. Sin embargo, a la fecha sigue sin funcionar porque los autores del programa, habitantes de la ciudad de México, no gestionaron ante la Comisión Federal de Electricidad el servicio especial de energía eléctrica que requiere la maquinaria para funcionar. El beneficio quedó abandonado sin que siquiera se le hubiera podido inaugurar.

No obstante todo lo anterior, actualmente un porcentaje considerable del café que se comercializa en la zona de Huauchinango y Xicotepec (Puebla) proviene de Pahuatlán, en específico de las comunidades nahuas de Xolotla y Mamiquetla. Ocurre incluso que empresas transnacionales, como Nestlé, mantienen una presencia constante entre los pequeños cafeticultores, a quienes ocasionalmente ofrecen créditos y asesoría a cambio de la venta del producto.

\section{LA PLAZA}

En los pueblos, la "plaza” es mucho más que el lugar en donde se realiza el intercambio de mercancías. Se trata del principal sitio de socialización y circulación de opinión pública. La plaza de Pahuatlán es una de las más vigorosos de la zona, y en el pasado lo fue más por el número de personas que convocaba y por el volumen de mercancías que movía. Su día "de plaza es el domingo".

Las comunidades indígenas también efectúan sus propias plazas: San Pablito el día sábado; Xolotla los viernes. A éstas asisten, por lo general, sólo gente de la respectiva comunidad, o bien, aunque en menor grado, gente de comunidades vecinas que comparten la filiación étnica. Los testimonios orales señalan que hace cuatro décadas era distinto; el día de mercado sanpableño atraía a muchos comer- 
ciantes y compradores otomíes de pueblos vecinos. El dato coincide con el registro que Dow hizo en la década de los setenta, ${ }^{65}$ años en los que la plaza se efectuaba durante tres días, lo cual contrasta con lo observado en el 2010. En efecto, los días martes se coloca un par de puestos en el centro y llega gente de pueblos aledaños a vender maíz. Los sanpableños no consideran que se trate propiamente de un día de plaza. La restricción en los días de mercado puede deberse al hecho de que los habitantes hayan relegado a segundo término la producción agrícola ante el auge de la producción y venta de artesanía de papel amate, aunque también existe la versión entre los lugareños de que la causa de esa disminución se debió a una norma que impuso el ayuntamiento:

Antes aquí se veían muchas cosas del campo: fruta, verdura, maíz, chile. Venían de otros pueblos de por acá de Hidalgo a comprar. Acá en la comunidad [San Pablito] la plaza era tres veces a la semana, ahora sólo un día a la semana. Después la presidencia [municipal] prohibió algunas plazas y la nuestra quedó para el día sábado. Con Xolotla y Atla [comunidades nahuas] fue lo mismo, allá les iba bien porque llegaban de Naupan a comprar, ahora su mercado es muy pequeño, sólo se ve un par de puestos (profesor, 50 años, otomí, San Pablito, Pahuatlán, 2007, 2008).

Al parecer, la imposición de prohibiciones para efectuar plazas en las comunidades indígenas fue una práctica a la que recurrieron las autoridades municipales desde el siglo XIX, con la finalidad de favorecer el mercado controlado por los mestizos pudientes de la cabecera municipal e impactar negativamente en la economía indígena, lo que parece aplicar, sobre todo, en el caso otomí, grupo antagónico de los mestizos de la cabecera municipal. Ante esto, los comerciantes otomíes y nahuas acuden a vender a la plaza de la cabecera, lo cual no necesariamente significa mejores ventas, pero sí un gasto en el traslado y el pago correspondiente por instalar sus puestos.

${ }^{65}$ James W. Dow, Santos y supervivencias, trad. Antonieta S.M. de Hope (México: INI, 1974). 
Velázquez señala que el funcionamiento de las plazas comunitarias en la región serrana se fue transformando debido a la conjunción de diversas causas, entre ellas: la disminución de la producción agrícola y la creación de nuevos caminos y carreteras. ${ }^{66}$

Desde hace al menos cinco décadas, la plaza municipal se efectúa en Pahuatlán de Valle los domingos. Durante todo el periodo temporal en el que se concentra este estudio (1960-2010), involucró a comerciantes del municipio y de municipios vecinos, pero a partir de la segunda década del nuevo siglo cada vez es menos. En las décadas pasadas, el tianguis dominical tuvo cierta relevancia regional en la Huasteca poblana y sus colindancias hidalguenses, de importancia sólo por debajo de aquellas grandes plazas de Huauchinango, Xicotepec, Acaxochitlán y Tulancingo. Figuró como tal desde mediados del siglo pasado, cuando menos. Además de la compra-venta de distintos productos, la plaza pahuateca era un espacio idóneo para entablar redes y contactos diversos. En la primera mitad del siglo xx, se daban cita arrieros, o bien, aquellos comerciantes que llegaban de puntos lejanos a través del ferrocarril -que llegaba a Chila (municipio Honey, Puebla)-, con la intención de comprar las cosechas directamente a los productores para posteriormente revenderlas.

En este mercado dominical, después de los mestizos de la cabecera municipal, son los otomíes de San Pablito quienes ocupaban y todavía ocupan algunos puestos en la plaza; desde hace tres décadas (1980-2010) se han mantenido vigentes ofreciendo su artesanía. ${ }^{67}$ En el caso de los nahuas de Xolotla, algunas familias vendían y aún venden en la plaza de la cabecera el café cultivado por ellas. Entre semana lo venden a intermediarios o lo comercializan en Xicotepec de Juárez, Huauchinango (Puebla), Tulancingo (Hidalgo) y el Distrito Federal, además de que hay un grupo que lo entrega directamente a la compañía Nestlé.

No obstante esa actividad, al día de hoy, mestizos e indígenas nahuas y otomíes insisten en que la relevancia de la plaza de Pahuatlán ha menguado. En los setenta llegaban vendedores y comprado-

${ }^{66}$ Velázquez, Cuando los arrieros.

${ }^{67}$ Amate, tenangos, bordados y bisutería en chaquira. 
res de distintas partes de la sierra, lo que es un indicio de la importancia relativa que tuvo la producción agrícola local. Entonces, la plaza de Pahuatlán cabecera no sólo era un mercado de importancia regional. Además, por la ruta que hacía escala en Pahuatlán cruzaba mucha gente que iba con dirección a Castillo de Teayo y Tuxpan (Veracruz). Había quienes iban de Tamiahua (Veracruz) a Pahuatlán, exclusivamente para vender pescado los días viernes y domingos. En ese sentido, es común escuchar frases como “ Nosotros estábamos acostumbrados a comer pescado! ¡Ahora hasta eso ha cambiado!”, lo que sugiere que, además de la posible disminución de ingresos para algunos, la dieta también se modificó e, incluso, empobreció.

Desde hace algunos pocos años, la plaza dominical de la cabecera sólo aloja a comerciantes del propio municipio de Pahuatlán. Ya no se ve más a los otomíes de Chila (municipio Honey, Puebla), quienes ofrecían tomate, jitomate, plátano, chile serrano y algunas leguminosas, como tampoco a los nahuas de Santa Ana Tzacuala o Santa Catarina (municipio Acaxochitlán, Hidalgo), quienes vendían granos, espinosos, tomates, cuatomates, chiles habaneros y una amplia variedad de setas, hongos y champiñones. La ausencia de comerciantes y compradores de municipios vecinos, notoria desde el ańo 2011, no parece tener que ver con la disminución de la producción agrícola o de otro género de enseres, sino con el nombramiento de "pueblo mágico" que recibió Pahuatlán de Valle ese preciso año. El título generó descontentos de diferente índole entre los otomíes y nahuas, así como entre mestizos, lo mismo pobres que acaudalados.

La categoría de pueblo mágico, que otorga el gobierno federal, busca resaltar los atractivos naturales, históricos y culturales de las regiones y comunidades rurales del país. Básicamente, se trata de una estrategia gubernamental que fomenta el "turismo cultural" y que, en algunos casos -como el que se presenta en el municipio de Pahuatlán-, más que beneficios, tiene implicaciones sociales y económicas negativas para los habitantes. En nuestro caso, supuso un reordenamiento de los comerciantes que favoreció a algunos pocos y perjudicó a muchos. Más aún, el nombramiento y las transformaciones que llevó consigo intensificaron las enemistades entre los 
mestizos de la cabecera municipal y los indígenas, ya que, según estos últimos, el único y verdadero motivo de haber recibido la etiqueta de pueblo mágico es la riqueza de las prácticas culturales otomíes y nahuas, y no, en cambio, valor alguno aportado por la población mestiza, en cuyo "pueblo mágico" se concentra la exigua derrama económica que lleva consigo el turismo.

¿Quiénes son realmente los beneficiados de dicho nombramiento? ¿Cuáles son los costos de mantener dicho nombramiento? Independientemente de la posible derrama económica que este nombramiento genera, es un hecho que los primeros en beneficiarse fueron los inversionistas externos a las localidades, así como aquellos encargados de ejecutar las obras de infraestructura y remodelación de los "mágicos" espacios públicos del pueblo. La remodelación arquitectónica del primer cuadro benefició específicamente a los viejos propietarios abarroteros y hoteleros.

La denominación de pueblo mágico obligó al ayuntamiento a tomar un conjunto de medidas sobre la plaza céntrica, con el fin de dar cumplimiento a los criterios que exige el programa federal. En vez de conservar la vieja plaza dominical como en ańos pasados, se le convirtió en un espacio de exhibición y tránsito para cierto tipo de turismo nacional e internacional. La idea es simular un pueblo con "encanto" y "tradición", como si todo, incluidos habitantes, formase parte de un guion museológico, muy en el estilo de un cuadro costumbrista. ${ }^{68}$

$\mathrm{Al}$ respecto, el ayuntamiento impuso normas que establecen que los comerciantes al menudeo ya no deben instalarse en el primer plano, frente a la presidencia y la iglesia, pues, estropean el paisaje o la vista que buscan los fuereños. Ahora la menguada plaza está detrás de la iglesia y en unas calles aledańas, donde "no afean" el panorama. Ciertas imposiciones relacionados con las características en los puestos, así como conflictos constantes con el ayuntamiento, generaron que algunos vendedores dejaran de asistir a ofrecer o comprar sus productos. Algunos lugareños han optado incluso por

${ }^{68}$ En relación con el tema de pueblos mágicos en Pahuatlán, véase Libertad Mora Martínez, "Por un proyecto en el que los indígenas sean protagonistas de su cultura", La Jornada de Oriente, 15 de octubre de 2015. 
acudir a la plaza vecina de Honey, también efectuada el día domingo, plaza que, por cierto, hacía años había perdido importancia frente a la de Pahuatlán.

\section{El comercio agrícola fuera de Pahuatlán}

Para vender sus cosechas de café, cacahuate, chile, panela, zapote, calabaza y otros vegetales, indígenas y mestizos del municipio de Pahuatlán no se limitaron nunca a las plazas de sus propias comunidades y de la cabecera municipal. Diversos puntos en el sur de la Huasteca y el Altiplano se cuentan entre los sitios a los que se trasladaban para vender sus productos. Acudían, en específico, a aquellos lugares en donde ya estaban acreditados a raíz de la venta a intermediarios. Es decir que visitaban los sitios en donde sabían que los compradores revendían. Ése fue el caso de la panela y el café de los nahuas de Xolotla, así como del cacahuate de los otomíes de San Pablito.

Este comercio agrícola podía ser al menudeo o al mayoreo. En el primer caso, consistía en "ranchear" o, más frecuentemente, vender directamente a algunos negocios o puestos establecidos en las "plazas”. En estos casos, solían ir los varones en compañía de la esposa o los hijos. Este comercio a pequeńa escala, para el que no era necesario permanecer varios días fuera de la comunidad, se efectuaba en los mercados de Tulancingo, Metepec, Apulco, Acaxochitlán (Hidalgo), Huayacocotla (Veracruz), Honey, Huauchinango, Xicotepec de Juárez y Tlacuilotepec (Puebla), los primeros cuatro parcial o enteramente en el Altiplano geográfico, aunque formen parte de la misma región cultural huasteca meridional.

Tanto entre otomíes como entre nahuas, generalmente eran los hombres "jefes de familia”, con dominio de las lenguas indígena y espańola, quienes trataban con los intermediarios y hacían los acuerdos de venta al mayoreo. Una vez formalizados dichos acuerdos -o sólo el primero de éstos-, su seguimiento -ya fueran ventas sucesivas o simplemente la entrega de la mercancía- podía hacerlo otra persona de menor rango, por ejemplo, alguno de los hijos.

A partir de los ochenta, los productores y comerciantes indígenas de Pahuatlán ampliaron paulatinamente su mercado agrícola. 
Algunos optaron por moverse al Estado de México y al Distrito Federal. Allá ofrecían sus cosechas, ya sea en pequeños tianguis o en mercados grandes, como la central de abastos de la Ciudad de México, adonde los productores y comerciantes nahuas y otomíes de Xolotla y San Pablito han llevado por años sus cosechas de café (molido), cacahuate, panela, chile, tomate, jitomate, zapote, entre otros.

Durante esa década de 1980, los jóvenes nahuas llegaron al centro del país para ofrecer sus cultivos y simultáneamente buscar trabajo en los negocios que encontraron a mitad de camino, en las rutas por las que transitaban con rumbo a los mercados para ofrecer su café. Esas nuevas vivencias y relaciones facilitaron que en ańos posteriores la opción de salir de sus comunidades cobrara relevancia. Hay que destacar que esto no sucedió con el grupo otomí, pues, la actividad artesanal generó otros procesos comunitarios que más adelante serán explicados.

Cuando los sanpableńos y los nahuas de Xolotla comenzaron a practicar este comercio que realizaban en la Ciudad de México, sólo viajaban los hombres adultos, a veces acompañados de sus hijos varones, algún hermano u otro familiar. Se transportaban en ferrocarril o vehículo automotriz. Este tipo de comercio no implicaba una movilidad estacional. A pesar de que no suponía una estancia prolongada fuera del hogar, estos viajes desencadenaron algunos sucesos de relevancia, entre los que se cuenta la vinculación con personas de otros sitios y la creación de nuevos contactos laborales. En el Distrito Federal y el Estado de México estrecharon vínculos con otros campesinos de diferentes zonas del país, que también llegaban a vender sus cosechas, o con paisanos que se habían instalado en la Ciudad de México en busca de un empleo que les redituara más dinero que el recibido por sus cultivos.

La percepción recurrente entre nahuas y otomíes en cuanto a la producción del campo y el dinero es, en efecto, que el comercio agrícola no es suficiente para generar algún tipo de capital económico que les permita mejorar sus ingresos, como sí ocurre con la migración internacional, o, en el caso de los otomíes sanpableños, con el comercio artesanal. Los testimonios nahuas y otomíes coinciden en que las cosechas, ya sea al menudeo o mayoreo, por lo general, "no son bien 


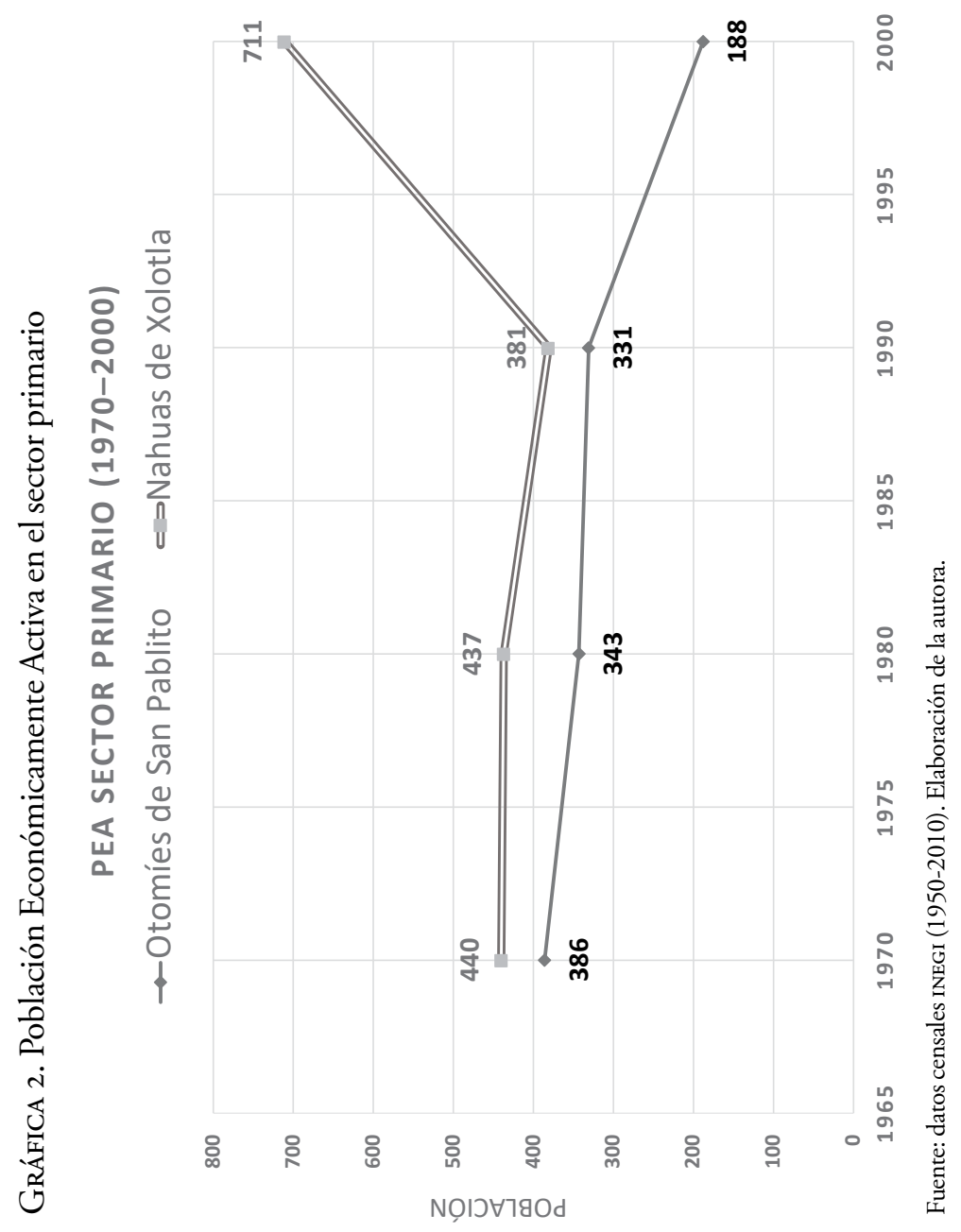


pagadas". Sin embargo, el dinero recibido por el comercio agrícola les sirve para mantener las tierras de cultivo, sacar las cosechas y juntar algún dinero que, "por poco que sea", sirve para iniciar otras actividades, ya sea diversificar los cultivos o inmiscuirse en nuevos oficios. "Le damos vuelta al dinero", señalan. Al respecto, resulta pertinente la propuesta de Warman en cuanto a que "el campesino es el segmento social que a través de una relación productiva con la tierra logra subsistir sin acumular". ${ }^{69}$

En la actividad agrícola intervenían tanto hombres como mujeres, en una u otra de las labores relacionadas con el comercio de los cultivos. Así fue para las generaciones pasadas, hasta que el comercio de los productos del campo decayó paulatinamente. A partir de los noventa, buscar trabajo fuera de las localidades de origen se convirtió en una práctica importante para la economía familiar. Warman señala que la relación del campesino con la tierra no excluye que tenga otras actividades productivas. Por el contrario, a veces las requiere como complemento. ${ }^{70}$ Es el caso por supuesto de los otomíes y nahuas de San Pablito y Xolotla, quienes se sostienen económicamente gracias a la combinación de diferentes actividades. Es claro que, desde la década de los ochenta y muy claramente desde los noventa, se intensifican las pluriactividades.

\section{Comercio ARTESANAL}

Otra de las alternativas económicas recurrentes de la nueva ruralidad es la elaboración de artesanías y su venta. Pérez C. incorpora en su definición de medio rural una diversidad de actividades entre las cuales menciona, además de la agricultura: "la artesanía, las industrias pequeńas y medianas, el comercio, los servicios, la ganadería, la pesca, la minería, la extracción de recursos naturales y el turismo". ${ }^{71}$

${ }^{69}$ Warman, Ensayos sobre el campesinado, 119.

${ }^{70} \mathrm{Ibid}$., 117, citado en Arias, "Nueva ruralidad", 125. Lo mismo que hoy ocurre con la migración y la actividad artesanal, estas actividades campesinas requieren de otras, complementarias, para mantener aquéllas de las que no siempre se obtienen los resultados esperados, ya sea como ingresos en efectivo, remesas o cosechas agrícolas.

${ }^{71}$ Edelmira Pérez C., "Hacia una nueva visión de lo rural", en ¿Una nueva ruralidad 
En este apartado destaco cómo es que la artesanía genera cierto tipo de pequeñas empresas y cómo se vincula en ciertos casos con el turismo local. La actividad artesanal es una de las ocupaciones características del municipio de Pahuatlán. Aunque se trata de un oficio protagonizado sobre todo por otomíes, se observa que tanto mestizos como indígenas nahuas y hñähñü se benefician y participan de la artesanía, directa e indirectamente.

Las mujeres nahuas de Xolotla elaboran algunos textiles. Los hacen principalmente para el uso personal, aunque también, en menor medida, para la venta a turistas o foráneos que llegan a la plaza dominical del municipio. Estos textiles nahuas los fabrican con técnicas tradicionales, por ejemplo, usando el telar de cintura y bordando en punto de cruz, realizando fajas y blusas, así como servilletas que son utilizadas en la cocina. No se trata de una actividad en la que participe un porcentaje considerable de la comunidad y tampoco representa un ingreso económico fijo y adicional a la economía doméstica.

Caso contrario es el de los otomíes de San Pablito. Con ellos, la actividad artesanal ha cobrado una connotación más allá del ámbito económico: ha transformado las relaciones sociales entre indígenas y mestizos en el municipio, además de haber generado un ingreso económico sin precedente para las familias. La artesanía es el medio que ha empoderado a los otomíes frente a los mestizos en general, y los poderosos mestizos de la cabecera municipal en específico. Un artesano otomí lo expresó así en 2015: “¡Si Pahuatlán es pueblo mágico es por nosotros, por nuestra cultura! ¿Qué hacen o qué tienen los de la cabecera? ¡Nada!”

La década de los sesenta fue crucial para los sanpableños, pues, de la mano con el comercio agrícola, iniciaron un comercio artesanal sin precedentes en el grupo ni en la región. El asunto remite en primera instancia al "amate", como se le conoce coloquialmente al primer objeto a partir del cual se elabora la artesanía otomí. En sus inicios y como desde tiempos remotos, fue con la corteza interna (la "cáscara") de la especie forestal llamada precisamente amate, con la

en América Latina?, comp. Norma Giarracca, 17-29 (Buenos Aires: ClACSO, ASDI, 2001), 17, citado en Grajales y Concheiro, "Nueva ruralidad", 153. 
que se elaboraba papel conforme a las antiguas técnicas prehispánicas. ${ }^{72}$ Sin embargo, dada la demanda económica que tuvo y debido a la ausencia de un programa sustentable, el árbol desapareció de las tierras de la comunidad y de zonas aledañas. Se adoptaron entonces nuevas especies forestales, como el jonote y la mora. ${ }^{73}$

Como he sugerido, el hecho de que se comercialice el papel entre los otomíes sanpableńos tiene connotaciones varias. Una de ellas tiene que ver con el carácter simbólico y ritual tanto del papel, sobre todo, de las figuras fitoantropomorfas plasmadas o creadas en éste. Ésta es una tradición que los otomíes sanpableños comparten con prácticamente todos los otomíes orientales (es decir, otomíes de la región cultural huasteca) y otros grupos indígenas del sur de la Huasteca. ${ }^{74}$ Tradicionalmente, los únicos que están autorizados para utilizar las figuras en rituales agrícolas, del ciclo de vida, terapéuticos (para sanar) o para dañar, son los curanderos o chamanes. ${ }^{75}$ Ellos poseen el conocimiento para recortar, así el don como designio divino y como lo que suele llamarse eficacia simbólica, ins1973).

${ }^{72}$ Hans Lenz, El papel indígena mexicano (México: Secretaría de Educación Pública,

${ }^{73}$ Estas especies forestales todavía se encontraban en San Pablito hasta la década de los noventa. Actualmente, los productores sanpableńos compran la corteza a mestizos de los municipios huastecos poblanos de Tlaxco y Xicotepec. La desaparición en el municipio de las especies arbóreas referidas, evidencia la importancia que tiene la implementación y seguimiento de programas de uso sustentable de recursos naturales.

${ }^{74}$ Sobre el papel amate de San Pablito, véase Libertad Mora Martínez, "Reconfiguraciones culturales y estrategias de sobrevivencia otomí, en San Pablito, Pahuatlán” (Tesis de licenciatura en Antropología Social, BUAP, Ciesas, 2008). Otomíes, nahuas y tepehuas del sur de la Huasteca utilizan el papel, amate o no, con fines rituales. Alan R. Sandstrom y Pamela Effrein Sandstrom, Traditional Papermaking and Paper Cult Figures of Mexico (Norman: University of Oklahoma Press, 1986). Aunque en menor medida, también ha sido registrado en algunos pocos casos totonacos de la misma región. Alain Ichon, $\mathrm{La}$ religión de los totonacas de la sierra, trad. José Arenas (México: INI, 1973).

${ }^{75}$ La tradición ritual de confección de figuras rituales ("muñecos"), habría sido inventada por los especialistas rituales otomíes entre finales de la época colonial y mediados del siglo XIX, según propone Guy Stresser-Péan, El Sol-Dios y Cristo. La cristianización de los indios de México vista desde la Sierra de Puebla, trad. Roberto Rueda Monreal y Arturo Vázquez Barrón (México: Fondo de Cultura Económica, Conaculta, CEMCA, 2011), 224-226. Galinier, por su lado, remite directamente dicha tradición a la época prehispánica. Jacques Galinier, "Iconografía otomí y nomadismo del sujeto". Alteridades 21(42) (2011): 165-175. 
pirados en la propuesta de Lévi-Strauss. ${ }^{76}$ No obstante, en el caso de los otomíes de San Pablito se presenta algo distinto. Es la única comunidad en la que, al tiempo que mantiene su importancia en las prácticas rituales, el papel se comercializa en pliegos y otros formatos, pero también se venden las figuras de tradición chamánica, confeccionadas por curanderos y por artesanos. El amate, lejos de perder su relevancia cultural, se resignifica.

La historia oral sanpableña relata que, en los sesenta, un grupo de extranjeros recorría Pahuatlán; entre ellos un japonés que, al observar el papel ritual y atraído por la pieza, solicitó un pliego. Tiempo después, esa misma persona regresó a la comunidad para hacer un gran pedido de pliegos de papel, con la finalidad de llevarlos fuera del país. En esa ocasión, y con la intención de poder entregar el pedido en tiempo y forma, fue que buena parte de la comunidad participó en la elaboración del papel amate, generando que, una vez entregado ese pedido, algunos siguieran elaborando los pliegos de papel, aunque sin la certeza de contar con compradores y mucho menos con un mercado estable para su venta.

Esa incertidumbre desapareció a partir del encuentro de los sanpableños con los nahuas del alto río Balsas guerrerense, en el mercado dominical de San Jacinto, en el Distrito Federal. A partir de entonces, inician el comercio de lo que hoy conocemos como las artesanías en papel amate. Los nahuas de Ameyaltepec y Xalitla (Guerrero), elaboraban y vendían un tipo de artesanía particular: cerámica decorada con pinturas e iconografía que expresan motivos relacionados con la vida cotidiana y festiva de su pueblo y cultura. Atraídos por la consistencia del papel y, sobre todo, por las posibles ventajas para transportarlo, pues, la cerámica es muy frágil, los artesanos nahuas de Amayaltepec compraron algunos pliegos lisos y pequeños. Fue así cómo nació una de las tradiciones artesanales y artísticas más importantes del centro de México. Paralelamente a la experiencia de los nahuas de Guerrero, los otomíes de San Pablito comenzaron a experimentar con su propio papel. Primero lo pintaron y después

${ }^{76}$ Claude Lévi-Strauss, Antropología estructural, trad. Eliseo Verón, 211-227 (Barcelona: Altaya, 1994). 
desarrollaron todo género de figuras seculares. Incluso los antiguos bordados han sido llevados al cuerpo del papel. El testimonio de unos artesanos sanpableños lo describe de la siguiente manera:

\begin{abstract}
Aquí en la plaza [el mercado de San Ángel] nos conocimos con los nahuas de Guerrero, mientras esperábamos la venta fue que un señor de Xalitla se acercó con un paisano de San Pablo y le pidió un pliego de papel. Aquellos pliegos eran chicos, lisos y no tan vistosos como ahora. Al señor se le ocurrió pintar sobre ese pedazo de amate, le gustó y fue así que ellos [los nahuas de Guerrero] comenzaron a pintar sobre amate y nosotros [los otomíes de San Pablito] iniciamos la venta de pliegos lisos de amate. Ahora nosotros también ya pintamos con acrílico sobre amate, eso lo hacen bien los jóvenes de San Pablito (artesano, 55 años, e hija, 15 años, otomíes de San Pablito, ciudad de México, 2010).
\end{abstract}

Tras la comercialización tanto del amate liso que vendían a los nahuas de Guerrero, como del papel decorado con pintura acrílica que ofertaban en los tianguis del sur de la Ciudad de México, las ciudades de Pachuca (Hidalgo) y Puebla se volvieron puntos importantes para la venta, en especial, los tianguis y bazares artesanales. Después figuraron los estados de Morelos y Michoacán, así como diversos puntos turísticos del país, como las playas de Veracruz, Guerrero y Jalisco.

De la mano con el comercio del papel amate de finales de los sesenta y que ha prevalecido hasta la fecha, fueron agregando otras artesanías a su cartera de mercancías. Una de ellas es la bisutería elaborada con cuentas de chaquira. Hasta hace un par de décadas, eran trabajos elaborados con poca destreza en los modelos y en los diseńos, sobre todo, si se les compara con piezas wixaritari (huicholas). Sin embargo, paulatinamente y tras años de dedicación al trabajo artesanal y la competencia entre pares, hoy podemos encontrar amplia variedad de piezas que exhiben un estilo e iconografías característicos del grupo otomí sanpableño. ${ }^{77}$ La chaquira la venden al

${ }_{77}$ Con cuentas de chaquira se elaboran llaveros, collares, gargantillas, pulseras, anillos, blusas, así como piezas que conforman parte de la indumentaria y parafernalia del Carnaval. 
menudeo y mayoreo. Para satisfacer esta demanda contratan trabajadores a destajo, sobre todo mujeres solas de comunidades mestizas de los municipios vecinos de Tlacuilotepec (Puebla) y Acaxochitlán (Hidalgo), mujeres cuyos esposos han emigrado temporalmente a los Estados Unidos.

Otra de las artesanías importantes entre los sanpableños son los textiles. Se trata de piezas elaboradas por ellos, entre las que destacan blusas con aplicaciones bordadas con técnica de pepenado o punto de cruz, así como el "queshqueme" (quechquémitl, en lengua náhuatl) tejido en curva. Los "tenangos" son otro tipo de textiles característicos de los otomíes orientales, cuya tradición fue inventada en las vecinas comunidades otomíes de Tenango de Doria (Hidalgo); de allí su nombre. ${ }^{78}$ En estos tenangos que adornan lo mismo servilletas que manteles o fundas de cojines, se representa flora y fauna, a veces mitológica, así como "historias" que retratan la vida cotidiana y ceremonial, por ejemplo, una fiesta patronal, una danza, entre otros motivos.

Por último, hay que señalar la artesanía que surgió a inicios del nuevo siglo. Ésta tiene fines de ornato y para su realización se requiere como materia prima el "tule", otra especie vegetal, sólo que en este caso se trata de una planta acuática, la cual consiguen directamente los varones de San Pablito en un municipio de la región cultural del Valle del Mezquital: Ixmiquilpan (Hidalgo). Con esta innovación se amplía la gama artesanal. Hay que destacar que la consistencia de esta especie es más resistente, en comparación con el jonote o la mora. En función de esta característica, se elaboran cuadros de diferentes tamańos o lámparas. Sin embargo, no es una artesanía que los sanpableños consideren que tenga la misma relevancia económica y cultural que el amate.

El comercio artesanal sí implica una movilidad laboral estacional, a diferencia del comercio agrícola que no requería de una estancia temporal fuera de la comunidad. Por lo regular, para la venta artesanal primero viajan algunos miembros de la familia en busca de posibles mercados, después se llevan a alguien más del pueblo, ya sea

${ }^{78}$ Elena Vázquez y de los Santos, Los Tenangos. Mitos y ritos bordados. Arte textil hidalguense (México: Conaculta, 2008). 
la pareja, hermanos o hijos, y se instalan a vivir en aquel lugar donde venden el amate y la chaquira. Regresan a su localidad tan pronto necesitan abastecerse de mercancía. Tal como lo señala un joven artesano otomí, la venta del papel amate requiere de gran movilidad en busca de nuevos mercados:

Vender el amate es salir y buscar nuevos lugares en donde no vendan otros de San Pablito, hay mucha competencia y cada vez bajan más los precios con tal de que le compren lo que llevan y así cada vez se la gana menos al papel. Nosotros fuimos a Chiapas, allá vendimos y también vimos otras artesanías, también sirve salir para darnos una idea de qué otras cosas hacer con el papel. De ahí nos movimos a la frontera sur y de ahí a Guatemala, allá vendimos en algunos lugares y compramos collares y pulseras de chaquira pero con otro estilo, diferente al de San Pablito. Aun así lo compramos y lo revendemos (G.P., artesano, 20 años, otomí de San Pablito, San Pablito, 2009).

Algunos otomíes de San Pablito que emigran a Estados Unidos también han aprovechado el viaje para buscar nuevos mercados en las ciudades mexicanas fronterizas, o bien han enviado artesanía a familiares que trabajan en aquel país para que ellos las vendan allá en donde, como reconocen, es bien pagado el trabajo artesanal.

En los viajes largos salen sólo los hombres acompañados de un hijo o hija. La siguiente vez puede ir la esposa acompañada de los hijos, o bien, ya sólo los hijos, aunque por lo regular las mujeres se van a los sitios en donde ya tienen un lugar fijo para la venta, como son los bazares artesanales del sur de la Ciudad de México, Tepoztlán (Morelos) y la ciudad de Puebla. Los viajes, por lo regular, los hacen en carros particulares propios, o pagan por el viaje a alguno de los jóvenes que trabajan como taxistas en la comunidad. Quienes venden en Puebla o en México viajan en camión. También ocurre que cuando un familiar ya encontró mercado fijo, se establecen a vivir en ese sitio y los hijos u otros familiares se encargan de abastecerlos de mercancía. Mientras tanto, en San Pablito, otros integrantes de la familia, o bien aquellos que son contratados por las familias mejor acreditadas en el negocio, trabajan en la manufactura de papel. 
Estos otomíes pueden tener un comercio de tipo directo o con intermediarios. Hay lugares a los que van a ofrecer su producción días antes de la fiesta; buscan a las personas con tiendas o puestos establecidos para que posteriormente las revendan. Así ocurre, por ejemplo, el 15 de septiembre, fecha en la que cobra relevancia la venta de chaquira; meses antes, las mujeres de la comunidad y las trabajadoras contratadas de comunidades vecinas, elaboran collares, pulseras, aretes y demás piezas en tonos tricolores. Este material lo venden al mayoreo en distintos lugares de la ciudad de México, donde revenden artesanía. No ocurre lo mismo en las vacaciones de verano, cuando los sanpableños se trasladan a las playas más visitadas de México, donde se instalan temporalmente para ofrecer de manera directa la artesanía, ya que, insisten, en esas fechas y en esos lugares es más fácil vender a buen precio.

Por otro lado, es importante señalar que algunos artesanos, particularmente diestros, elaboran piezas de amate consideradas originales, lo que ha generado que a muchos de ellos se les reconozca más como creadores de piezas de arte que como artesanos. Estos jóvenes que crean obras, ya sea pintando sobre el amate, o sirviéndose de éste como base, para dar forma a un conjunto de narraciones. No es extrańo encontrar en algunos museos o galerías de arte contemporáneo este tipo de piezas, que paulatinamente se han ido posicionando no como artesanía ni como arte popular o tradicional, sino como piezas de arte contemporáneo que remiten a un autor, con una técnica y factura únicas. Se trata de una generación de artesanos-artistas que buscan afanosamente abrirse camino por canales que no son los que transitaron sus padres ni abuelos. Paralelamente, se ha dado un reconocimiento a su trabajo por parte de galeristas y coleccionistas especializados, que ven en las expresiones del amate un estilo ecléctico emergente.

\section{MOVILIDAD LABORAL NACIONAL}

Otra de las alternativas fundamentales en las economías nahua y otomí, que ha prevalecido desde la década de los sesenta hasta la fecha, es la movilidad laboral. Se trata de otra de las actividades que 
caracterizan a la nueva ruralidad. Giarracca y Levy sugieren que a dicho fenómeno

le podemos agregar el incremento de las migraciones, la pluriactividad familiar y la multiocupación de las personas, el crecimiento de la densidad poblacional en las comunidades y pueblos (el fenómeno de la "rururbanización"), y la importancia de los territorios y lugares en la articulación de las estrategias familiares, de las nuevas protestas y movimientos sociales. ${ }^{79}$

Campbell sostiene que la movilidad es la esencia de la mundialización de la economía. ${ }^{80}$ Esto se puede constatar en muchos casos del país y de otras latitudes. Sin embargo, para fines de esta explicación y con base en los datos empíricos, se diferenciará el concepto de movilidad del de migración transnacional. Movilidad espacial alude al conjunto de desplazamiento en el espacio por parte de los individuos, cualesquiera sean la duración de la ausencia y la distancia del desplazamiento. ${ }^{81}$ El concepto de movilidad tiene la virtud de que toma en cuenta los movimientos de los sujetos, independientemente del tiempo que pasen en los nuevos sitios. Esto se observa en los distintos tipos de movilidad realizados tanto por nahuas como por otomíes en distintos periodos de tiempo, con modalidades y destinos varios; por ejemplo, a puntos específicos de la región y al Distrito Federal, así como a aquellos lugares en los que los nahuas comercializan la flor, como expondré en este mismo apartado, o, como expuse antes, los otomíes y la artesanía; o bien, en décadas pasadas, cuando ambos grupos vendían su producción agrícola. Dando seguimiento a esta explicación, se esbozarán algunas de esas movilidades, para distinguirlas de la alternativa migratoria transnacional que describiré en el siguiente apartado.

Una vez que los precios del café cayeron dramáticamente en el último año de la década de los ochenta, y en mucho por las granizadas que azotaron la región, los cafeticultores de Xolotla comenzaron

${ }^{79}$ Giarracca y Levy, "Introducción. América Latina”, 22.

${ }^{80}$ Campbell, citado en Ramiro A. Flores Cruz, "La discusión en torno a la migración y la movilidad territorial de la población", 4 .

${ }^{81}$ Pellegrino, citado en Flores, "La discusión", 5. 
a buscar empleo fuera de su comunidad, en las ciudades de Puebla, Huauchinango (Puebla), Pachuca y Tulancingo (Hidalgo), pero también, y más relevantemente, al oriente de la Ciudad de México. El hecho de que en algún momento la venta de sus cosechas de café en la central de abastos del Distrito Federal tuviera cierta importancia, sirvió para que en años posteriores estos nahuas lograran afianzarse tanto en esa zona de la capital, como en ciertas actividades urbanas. Esto generó que algunos nahuas de Xolotla que buscaban empleo fuera de su comunidad, lo hicieran en ese lugar, valiéndose de contactos entablados a partir del comercio del cultivo del aromático.

En esta movilidad laboral sólo participaban hombres mayores de edad, bilingües, algunos sólo con estudios de educación básica. La oferta laboral en la central de abastos podía ser atendiendo los negocios, o bien como cargadores, diableros o ayudantes. Por lo general buscaban un empleo que les permitiera visitar con cierta regularidad a sus familias y participar en las actividades comunitarias, por ejemplo, cumplir con el sistema de cargos y mayordomías, o cosechar el café, ya que, si bien, las ventas al mayoreo sí tuvieron una disminución, al menudeo siguieron generando un pequeño ingreso en la economía doméstica.

Así como en los ochenta los hñahñü de San Pablito gozaban de los beneficios del apogeo del comercio artesanal del amate y la bisutería de chaquira, entre los nahuas de Xolotla cobró auge la opción de buscar empleo temporalmente en el Distrito Federal. De esa forma y sin dejar el cultivo del café, invertían el pago que recibían en la ciudad para costear los gastos cotidianos e ir invirtiendo, ya fuera en arreglar paulatinamente su casa, sus pequeñas huertas, comprar algún terreno, o mandar a los hijos a la escuela. No obstante, hay que destacar que si el comercio del café no generó el ingreso suficiente para capitalizar a los productores, sí fue vital para la manutención doméstica; representó el ingreso económico principal para las familias de Xolotla y en menor grado de Mamiquetla (municipio Pahuatlán), pues, del comercio del café se beneficiaban directamente los cafeticultores, así como aquellos que se alquilaban para trabajar por un jornal con los nahuas de Xolotla.

Estos cafeticultores que comenzaron a laborar temporalmente fuera de Xolotla, al principio sólo fueron varones que regresaban 
por lo regular cada quince o veinte días a la comunidad, dependiendo del tipo de actividades y de los gastos que implicaba hacerlo, pues, si bien recibían un ingreso adicional a la actividad agrícola, éste también debía alcanzar para costear los gastos de manutención en el lugar adonde habían emigrado. Así, una vez afianzados en los nuevos sitios, alguna minoría de mujeres de Xolotla comenzaron a emigrar. Eran parejas, hermanas o conocidas de aquellos que previamente habían salido. Todas jóvenes bilingües con estudios de secundaria, se empleaban como ayudantes en negocios, en fábricas o en labores domésticas. Sin embargo, esta movilidad laboral femenina de las nahuas de Xolotla no fue representativa, pues, sólo una minoría optaba por emigrar. La mayoría preferían, por el contrario, quedarse con su familia, participar en la comunidad y dedicarse al café.

Junto con la actividad cafeticultora, hay que incluir otra alternativa económica entre los nahuas de Xolotla: la floricultura, negocio que inició con otros vecinos nahuas de la Huasteca poblana. El origen de esta actividad nos remite tan lejos como la década de los treinta del siglo pasado, a la localidad de Tenango de las Flores en Huauchinango (Puebla). ${ }^{82}$ En esta labor también influyeron, en las décadas siguientes, los nahuas de Naupan (Puebla), con quienes los de Xolotla mantenían y mantienen una serie de vínculos culturales y, más específicamente, religiosos denominacionales, producto de recientes procesos de conversión religiosa del catolicismo a diversas variantes evangélicas del cristianismo y a la iglesia constituida por los testigos de Jehová. Los vínculos laborales se establecieron cuando los indígenas de Naupan, ya entrado el nuevo milenio, buscaron gente que saliera a comercializar la flor que ellos previamente compraban en la Ciudad de México. Paulatinamente, los de Xolotla se incluyeron en esta nueva dinámica laboral, la cual reemplazó la posibilidad de emigrar a los Estados Unidos o asalariarse en la Ciudad de México, Puebla o Huauchinango, convirtiéndose en una opción viable para sumar un ingreso adicional al recibido por el ingreso económico del café y de otros servicios.

${ }^{82}$ Libertad Mora Martínez, "Huauchinango: vida y resignificaciones del pasado", en Huauchinango el rumor del tiempo, coord. Libertad Mora, 275-298 (Puebla: H. Ayuntamiento de Huauchinango 2011-2014, PIRED, 2011). 
Entre los nahuas de Xolotla, el comercio de flores es una actividad exclusiva de los varones, algunos son jóvenes que también se han dedicado al comercio del café o han emigrado al centro de México. La dinámica consiste en trasladarse de Xolotla a la Ciudad de México, ahí ellos recogen una variedad de plantas de ornato que previamente ha sido definida por sus vecinos de Naupan. Después se dirigen a ciudades como Durango, Querétaro y Monterrey, así como localidades pequeñas a su paso. A los hombres de Xolotla, los de Naupan les pagan por el viaje y por el total de la venta de las plantas. En el trayecto pueden pasar días e incluso meses fuera de su comunidad. Mientras tanto, en la comunidad surge una nueva organización en las labores domésticas y laborales, pues, a falta de hombres, son entonces las mujeres, los adolescentes y la gente mayor (los "viejos") quienes se encargan de los huertos de café que, en efecto, los grupos domésticos siguen atendiendo.

Se trata, esta última, de otra de las aristas que destaca el enfoque de nueva ruralidad: la participación e inmersión de las mujeres en actividades de las que, si bien ya eran participes indirectas desde tiempo atrás, ahora son ellas las que destacan por su participación en una serie de actividades alternativas que antes eran protagonizadas por los varones. Es el caso de la cafeticultura entre los nahuas de Xolotla en los setenta y ochenta, y después la participación femenina en el nuevo milenio. Es también el caso de los otomíes de San Pablito a partir de los noventa, cuando son las mujeres y los menores quienes apoyan en la elaboración de la artesanía en la comunidad, a partir de la ausencia de los varones que salen a vender su producto artesanal o, más tarde, incluso ellas incursionan en este tipo de movilidad laboral estacional, mientras que los varones se encuentran en los Estados Unidos. Hay que resaltar que, en general, hombres y mujeres de Xolotla, a diferencia del grupo otomí de San Pablito, no suelen pasar mucho tiempo fuera de su comunidad, pues, para los nahuas de Xolotla es relevante la presencia cotidiana con la familia y la comunidad, además de que en su propia comunidad y zonas aledañas, desde inicios de este siglo, se han generado una serie de actividades laborales bien remuneradas para ellos, muchas de éstas relacionadas con la migración transnacional otomí. 
Otros casos representativos son los de aquellos nahuas que se emplean en la albañilería. Quienes se dedican a este oficio salen de la comunidad cada vez que tienen un trabajo y retornan a Xolotla en cuanto lo terminan, es decir, cuando concluyen "la obra". La zona laboral es el municipio de Ecatepec de Morelos (Estado de México), o bien, buscan trabajo como albańiles en comunidades con alto índice de movilidad transfronteriza de la región, como ocurre entre sus vecinos otomíes de San Pablito o Santa Ana Hueytlalpan (municipio Tulancingo, Hidalgo) y San Nicolás (municipio Tenango de Doria, Hidalgo), a quienes la migración transnacional ha transformado notoriamente en su economía y paisaje comunitario. Ahí, más que en otras comunidades de la región, se pueden observar casas con dos o tres pisos, con acabados y estilos arquitectónicos que remiten a la costa este de los Estados Unidos de América. Entre otras ventajas, los constructores de Xolotla destacan que ese tipo de trabajo les evita viajar a otros sitios más lejanos, junto con los costos de vivir fuera de su comunidad (hospedaje, comida y servicios).

Algo similar se observa en el contexto festivo, pues, en la región se reconoce la virtud de los músicos nahuas de Xolotla, así como la fastuosidad de las fiestas que organizan los otomíes sanpableños, quienes suelen contratar músicos de Xolotla para acompañar el ciclo festivo. Si el calendario de las mayordomías en San Pablito se ha duplicado y reforzado desde al menos dos décadas a la fecha, a partir de la migración transnacional, esto se traduce en el doble de actividades festivas en las que la música no puede faltar. ${ }^{83}$ Es ahí donde los nahuas de Xolotla se hacen presentes a través del acompañamiento con banda de viento, pero también por aquellos que, contratados, elaboran arreglos florales para la iglesia.

Esto nos indica que tanto nahuas como mestizos de la región, son partícipes indirectos de la dinámica migratoria transnacional protagonizada por los otomíes sudhuastecos. Una vez afianzado el circuito migratorio de la sierra a la costa este de la Unión America-

${ }^{83}$ Mora, "Dinámicas migratorias". 
na, los hñähñü (otomíes) han generado distintos tipos de empleos en los que trabajan aquellos que optan por quedarse en la zona. ${ }^{84}$

Por su parte, entre los otomíes de San Pablito, la idea de buscar algún empleo fijo asalariado figuró a partir del segundo lustro del siglo xxI, pues, fue a partir del aumento en el índice de jóvenes que han acabado su bachillerato y algunos su licenciatura, que éstos buscaron asalariarse. Hay que puntualizar que se trata de las nuevas generaciones que han crecido en un contexto comunitario, social y económico, muy distinto del que vivieron sus padres y abuelos. Para los hñahñü, la actividad clave ha sido el comercio artesanal. Gracias a éste, tuvieron el ingreso económico necesario para poder emigrar de manera constante a los Estados Unidos y, en función de ello, han podido pagar los estudios de los niños y jóvenes de su comunidad. Sin duda, la capitalización social producto del comercio artesanal del amate abarca diversas aristas: desde lo económico, hasta lo social y político.

\section{MigRACIÓN TRANSNACIONAL HÑÄHÑÜ}

Como parte de las transformaciones sociales que podemos destacar en los dos casos que aquí nos ocupan, hay que enfatizar que las alternativas económicas que han imperado, al menos desde los sesenta y hasta la primera década del nuevo milenio, son ocupaciones que han permeado otros ámbitos más allá del económico, por ejemplo, el cultural, social o político. En ese sentido, una última alternativa por describir entre los otomíes y nahuas de este estudio, es la migración transnacional, actividad característica de la nueva ruralidad, enfoque con el cual he intentado explicar la economía indígena contemporánea. La migración es una de las ocupaciones recurrentes de la población, y en pleno siglo Xxi, tanto hombres como mujeres; niños, jóvenes y adultos son partícipes de movilidades y migraciones

En sintonía con Giarracca y Levy, creo que la decisión migratoria debe analizarse no sólo como una respuesta a la necesidad económica, "se trata de una estrategia social de sujetos que se oponen y no

${ }^{84}$ Libertad Mora Martínez, "De la Sierra a la Costa. Migración otomí transnacional: Los hñähñü de la Huasteca Poblana”. Migraciones Internacionales 9(34) (2018): 9-36. 
se resignan a una situación de arrinconamiento y exclusión" ${ }^{85}$ Es decir que se debe analizar a los actores sociales como constructores activos de su vida cotidiana. Ahondando en esto, retomé la propuesta de Hjorth en cuanto a que "los estudios migratorios tienen el desafío analítico de inscribir el objeto de estudio en un contexto macroestructural, y a su vez desarrollar una comprensión de las particularidades del fenómeno observado en el trabajo empírico". ${ }^{86}$ En ese sentido, revisé las condiciones estructurales en los distintos circuitos o etapas que han caracterizado la migración México-Estados Unidos, ${ }^{87}$ y después ubiqué el entorno microestructural: me refiero a las diferencias entre los otomíes de San Pablito y los nahuas de Xolotla: sus decisiones para emigrar o para permanecer en la comunidad, así como las razones para tomar una decisión en un sentido o en otro. A su vez, ambos contextos (macro/micro) están mediados por el nivel mesoestructural, es decir, el ámbito cultural que define o influye en la alternativa migratoria.

En el tema que aquí nos ocupa, cobran particular importancia los otomíes de San Pablito, quienes han consolidado un circuito migratorio eficaz que va de la sierra huasteca a la costa este de la Unión Americana. El caso de sus vecinos de San Nicolás (municipio Tenango de Doria, Hidalgo) es vital para entender los circuitos migratorios que se han establecido en la zona. En esta última comunidad, alrededor de los sesenta, la presencia de iglesias pentecostales y del personal del Instituto Lingüístico de Verano influyeron en la decisión de emigrar. Esos primeros emigrantes participaron en los últimos años del Programa Bracero (1942-1964), lo que motivó que, a finales de los setenta y, sobre todo, a partir de los ochenta, detonara la alternativa migratoria en pueblos vecinos, como en en Santa Ana Hueytlalpan (municipio Tulancingo, Hidalgo) y San Pablito. $^{88}$

${ }^{85}$ Giarracca y Levy, "Introducción. América Latina”, 20.

${ }^{86}$ Susann Vallentin Hjorth Boisen, "Migración, globalización y flujos transregionales. Etnografía del proceso migratorio del sur de Veracruz a la frontera norte” (Tesis doctoral, Universidad Autónoma de México, 2007), 8.

${ }^{87}$ Jorge Durand, Douglas S. Massey y Emilio Parrado, “The New Era of Mexican Migration to the United States", Journal of American History 86(2) (1999): 518-536.

${ }^{88}$ Posteriormente, también los otomíes de Pantepec (Puebla), Huehuetla (Hidalgo), 
Ambos grupos otomíes que se incorporaban al circuito migratorio, participaron de forma tardía en el periodo que Durand y otros llaman "la era de los indocumentados (1965-1986)", y plenamente en la que los mismos autores nombran "la era de 'la contradicción' (1986-1990)", ${ }^{89}$ periodo en el que muchos de los migrantes de primera generación obtuvieron documentos del programa IRCA (Inmigration Reform and Control Act, traducible como ley de reforma y control de inmigración), así como visas temporales, razón que alentó a familiares y paisanos a considerar la opción de emigrar. No obstante, en la "era de la marginalización (1990-2015)", ${ }^{90}$ empeoraron las condiciones para aquellos que deseaban probar suerte, pues, no obtuvieron documentos oficiales y las condiciones para cruzar la frontera norte se dificultaron por el aumento de policías fronterizos estadounidenses y, sobre todo, por la presencia de delincuencia organizada. Sin duda, las nuevas etapas estarán reguladas por las nuevas reformas migratorias y con el cambio de presidente en los Estados Unidos. Paulatinamente, las características de esos movimientos migratorios han ido cambiando, tanto en los actores sociales, como en las dinámicas laborales y las implicaciones para las comunidades de origen. Desde los ochenta hasta la fecha, los otomíes sudhuastecos han protagonizado los movimientos migratorios a la Unión Americana, fomentando novedosas formas de interacción en espacios transnacionales.

En el municipio de Pahuatlán, los sanpableños contaban con el capital económico para poder emigrar: el dinero obtenido del comercio artesanal desde los setenta que les permitía pagar los costos del traslado, el "coyote" o guía, así como sufragar su estancia en tanto obtenían empleo en aquel país. En esos años, por su parte, los nahuas de Xolotla se dedicaban mayoritariamente a la cafeticultura, actividad que si bien comenzaba a ser redituable a pequeńa escala, no les permitía juntar el dinero necesario para emigrar a los Estados Unidos. Sin embargo, la decisión entre los nahuas para "no dejar la co-

Ixhuatlán de Madero y Texcatepec (Veracruz) van a participar de este circuito migratorio, con destinos en distintos estados estadounidenses.

${ }^{89}$ Durand et al., "The New Era".

${ }^{90}$ Ibidem. 
munidad", no sólo refiere a causas económicas, en este caso, lo costoso del traslado, como intentaré explicar en las reflexiones finales.

Aunado al capital económico, con el paso de los años los sanpableños fueron reforzando algún tipo de capital social con sus vecinos otomíes en la región sudhuasteca, pero también con aquéllos ya instalados en Carolina del Norte, es decir, redes transnacionales intraétnicas. Este tipo de redes sirvió no sólo a quienes ya radicaban en aquel país, sino que también fue vital para los futuros migrantes otomíes de San Pablito. Al respecto, hay que recordar que, como sugerí en el apartado anterior, para los fines de este trabajo distingo entre movilidad laboral y migración transnacional, en específico, a partir del papel de las redes transnacionales que se han ido estableciendo a lo largo de tres décadas, vínculos que no se aprecian en la movilidad laboral nacional (comercio agrícola, artesanal y de flores) caracterizada por estancias breves y en ocasiones por movimientos inestables. En ese tenor, retomo la noción que propone Arango en cuanto a las redes establecidas entre migrantes transnacionales, a las cuales define como "conjuntos de relaciones interpersonales que vinculan a los inmigrantes, a emigrantes retornados o a candidatos a la emigración con sus parientes, amigos o compatriotas, ya sea en el país de origen o en el de destino". ${ }^{91}$

Hay que destacar que, en un primer momento, la migración transnacional hñähñü fue una actividad producto de la necesidad económica y, posteriormente, sin dejar de ser un medio que les genera importantes ingresos económicos para la manutención de las unidades domésticas, se convirtió en una estrategia y decisión de vida. Una estrategia económica así como sociocultural, pues, fue precisamente a partir de la migración a los Estados Unidos que se generaron redes transnacionales específicas, así como alianzas intraétnicas que influyeron en algún tipo de empoderamiento otomí frente a los mestizos de Pahuatlán y de la región. Este empoderamiento se expresa en las exigencias que dirigen a los mestizos de la cabecera municipal en general y del ayuntamiento en específico.

${ }^{91}$ Joaquín Arango, "La explicación teórica de las migraciones: luz y sombra”, Migración y Desarrollo (1) (2003): 20. 
Entre dichas exigencias, es notoria la de cierta autonomía en la toma de decisiones comunitarias, por ejemplo, en cuanto a instalaciones y servicios en la localidad. Este empoderamiento no se presentó en seguimiento de actividades como el comercio agrícola o artesanal, ni como consecuencia de la movilidad laboral.

Por otro lado, a nivel comunitario la migración transnacional también abonó en un reforzamiento y cohesión al interior del grupo. Un ejemplo es que un porcentaje considerable de las remesas enviadas a la comunidad son empleadas en las fiestas católicas o lúdicas, así como en ritos chamánicos comunitarios. Lejos de desaparecer este tipo de prácticas culturales, se observa que con la migración transnacional se han reforzado ostentosamente, además de reconfigurar la noción de territorio ligado a la comunidad, pues, es común que ciertos festejos, como el Carnaval o los huapangos, se realicen tanto en San Pablito como en Carolina del Norte, o que en los ritos chamánicos terapéuticos efectuados en la comunidad participen los ausentes a través del dinero que envían para su ejecución y por medio de su ropa. Los familiares que están en San Pablito acuden a los ritos chamánicos llevando en sus manos algunas prendas de los migrantes ausentes, los ritos de limpia que practican los curanderos sobre la ropa están destinados a quienes están lejos de casa.

Elementos como los señalados sugieren la importancia de esos ritos llamados Costumbres. Respecto a los ritos más convencionalmente católicos, hay quienes emigran para costear una mayordomía o imagen. Un testimonio etnográfico en campo señala: "Es como una inversión, si tú cooperas, todo se te regresa, si haces una buena fiesta, así te va ir más adelante". Esto se relaciona con el hecho de que a partir del año 2007 hubo un incremento en el envío de remesas. Como antes informé, el ciclo festivo se duplicó y aún más. En contraste con ańos pasados en los que la fiesta duraba tres o cinco días, actualmente dura dos semanas, con la celebración de dos imágenes de santos por día. Los lugareños sugieren que esto no lo hacen "ni siquiera los de la cabecera", los sanpableńos enaltecen que la fiesta, denominada recientemente Feria del Amate y de la Chaquira, es pagada en su totalidad por los otomíes, es decir, sin recibir apoyos gubernamentales como sí ocurre en la fiesta de la cabecera municipal. 
Foтo i. Artesana otomí de San Pablito, Pahuatlán, elaborando papel amate con incrustaciones de Tenangos

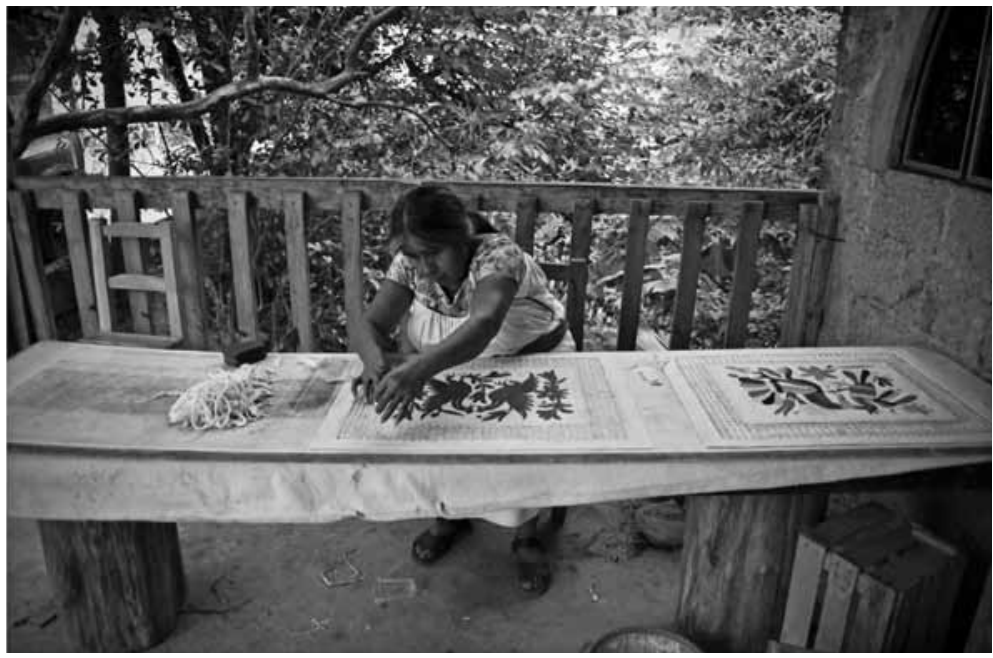

Fotografía de Libertad Mora, 2016.

En cuanto al ámbito individual, para algunos jóvenes varones, la emigración la podríamos describir metafóricamente como una especie de rito de paso. Los muchachos salen del bachillerato y algunos cuentan con el recurso económico para acceder a estudios universitarios, sin embargo, insisten en que antes de esto o de formar alguna relación estable con su pareja, deben ir a los Estados Unidos, así como lo hicieron sus hermanos o sus padres, una o dos generaciones previas.

Hay que agregar que con la migración transnacional se incrementan las pluriactividades de las personas, ya sea de quienes emigran o de quienes permanecen en la comunidad. Como indiqué en apartados anteriores, aunque la migración no es una alternativa recurrente o característica para los nahuas de Xolotla, han incursionado en una serie de actividades laborales a partir de la migración transnacional de sus vecinos otomíes. Ya sea como músicos en algunos festejos o en la albañilería, los nahuas son participes indirectos de la migración transnacional otomí. Así como el de los "xolotlas" 
que trabajan para los "sanpablos", podríamos señalar otros casos que obligan a considerar el incremento de la población y de los ingresos por las remesas, de la mano con la ausencia de buena parte de esa población que ha decidido emigrar para enviar esas remesas a casa. En ese escenario, se hace necesario satisfacer un incremento en la demanda de servicios, en los cuales intervienen indígenas y mestizos de diferentes partes del municipio.

En relación con las nuevas actividades en las que se emplean los sanpableńos migrantes en la costa este estadounidense, es recurrente que los varones sean contratados en la construcción de hogares o edificios. Aunque no se trata de una actividad en la cual tengan experiencia previa, indican que adquieren ese conocimiento con rapidez, con la ayuda que supone trabajar con equipos de conocidos o connacionales. También a partir de la migración como parte de una actividad de la nueva ruralidad, hay que señalar el fenómeno de la "rururbanización", pues, la "comunidad tradicional", ya se "rural o indígena", se ha ido transformando tanto en demografía, servicios locales y en la arquitectura en sus viviendas. No es extraño encontrar en San Pablito locales comerciales con letreros en dos o tres lenguas: otomí, español e inglés o, con mayor relevancia, como mencioné en un apartado anterior, casas de dos o tres pisos que imitan el estilo arquitectónico de aquellas que los sanpableños construyen en Carolina del Norte. Este tipo de viviendas no sustituye las tradicionales, sino que, ubicada en el mismo solar doméstico, a veces queda vacía durante algún tiempo o vive en ella algún miembro soltero de la familia extensa. Esas casas de estilo gringo son las únicas que los mismos sanpableños edifican. Para el resto contratan a nahuas o mestizos de la zona. Por su parte, las casas tradicionales tienen la especificidad de que están edificadas con la intención de elaborar allí la artesanía, de manera que se disponen algunos espacios con techo y paredes, otros igualmente techados pero sin paredes, y otros más completamente al aire libre.

En contraste con las mujeres, los hombres suelen pasar más años en los Estados Unidos, un lustro cuando menos y a veces hasta dos décadas. De hecho, algunos hombres que emigraron en los ochenta aún no retornan de manera definitiva a San Pablito; pasan algunas temporadas largas en la comunidad y luego regresan al Norte. Los 


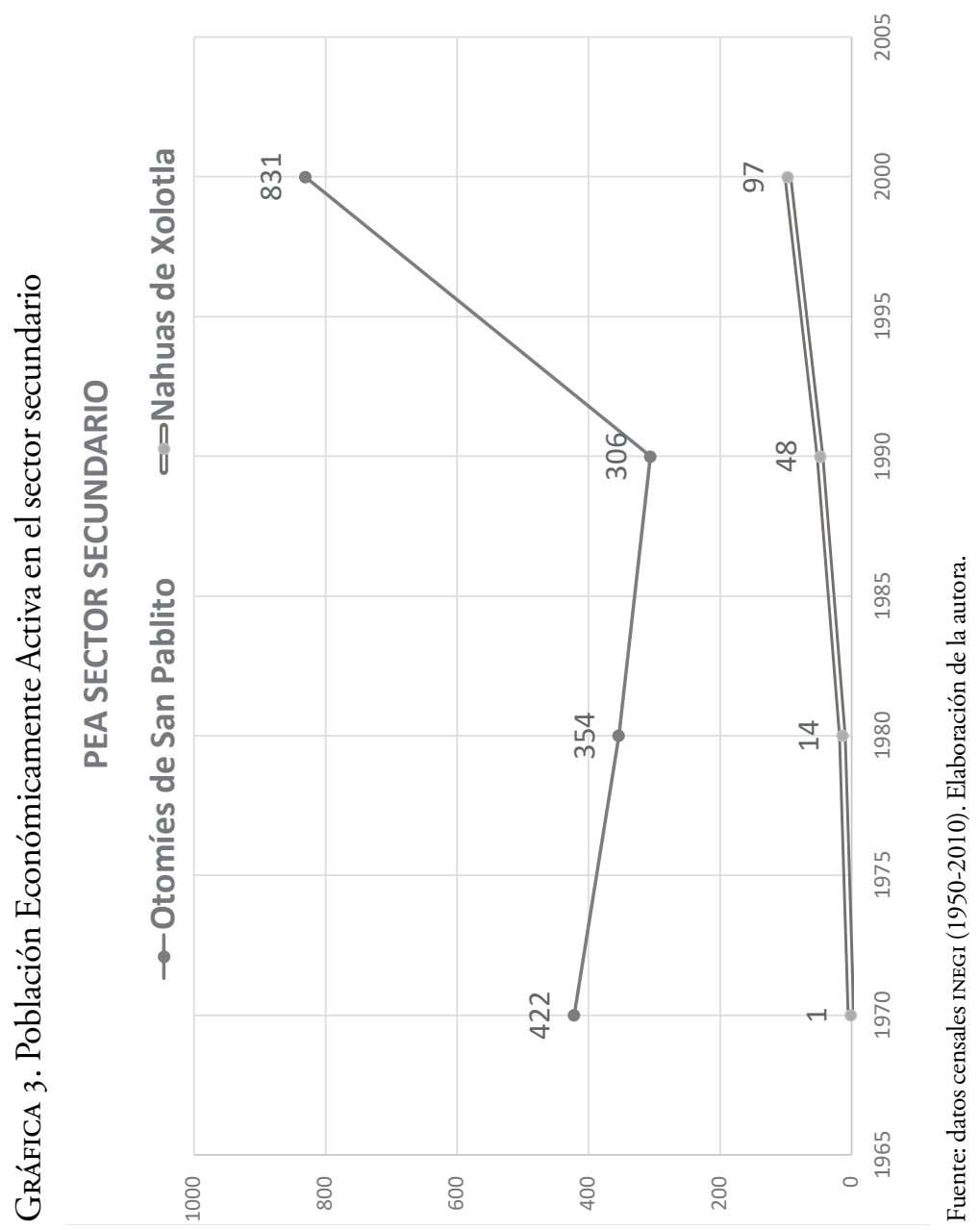


Foто 2. Cafeticultores nahuas de Xolotla Pahuatlán en festejo de Todo Santos

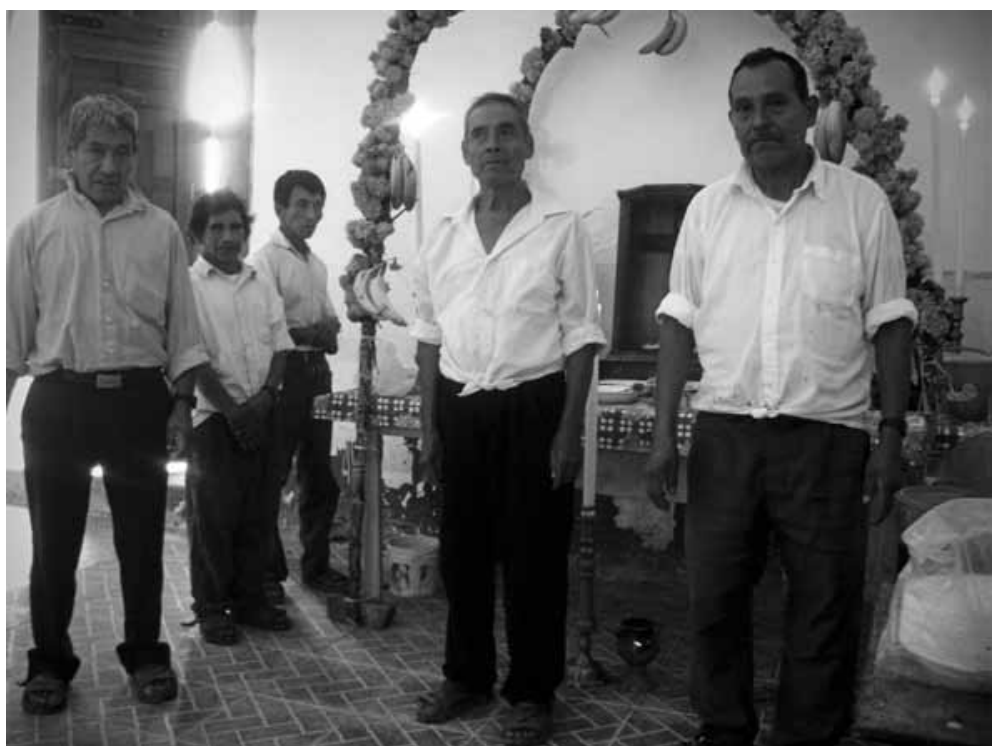

Fotografía de Libertad Mora, 2007.

emigrantes procuran regresar a la comunidad en fechas previas a Todo Santos u otros festejos. Todos coinciden en que deben juntar e invertir su dinero en la comunidad, conscientes de que sólo durante su juventud y primera parte de su vida adulta conseguirán un trabajo y, sobre todo, aguantarán las jornadas laborales en aquel país. En efecto, muchos optan por laborar dos jornadas diarias, es decir, alrededor de 16 horas: "Ya vendrán otros tiempos, de viejos ya nos dedicaremos a la artesanía y de eso vamos viviendo, pero mientras, hay que aprovechar y chingarle", insistiendo en que ni del campo ni de la artesanía han logrado el ingreso económico obtenido de la migración a Carolina del Norte. Con el sueldo recibido pueden comprar un automóvil que, después de un par de años, a lo sumo, convertirán en taxi. De hecho, muchos hijos o hermanos de emigrantes trabajan como taxistas, haciendo viajes de San Pablito a Pahuatlán cabecera o a la ciudad hidalguense de Tulancingo. Tam- 


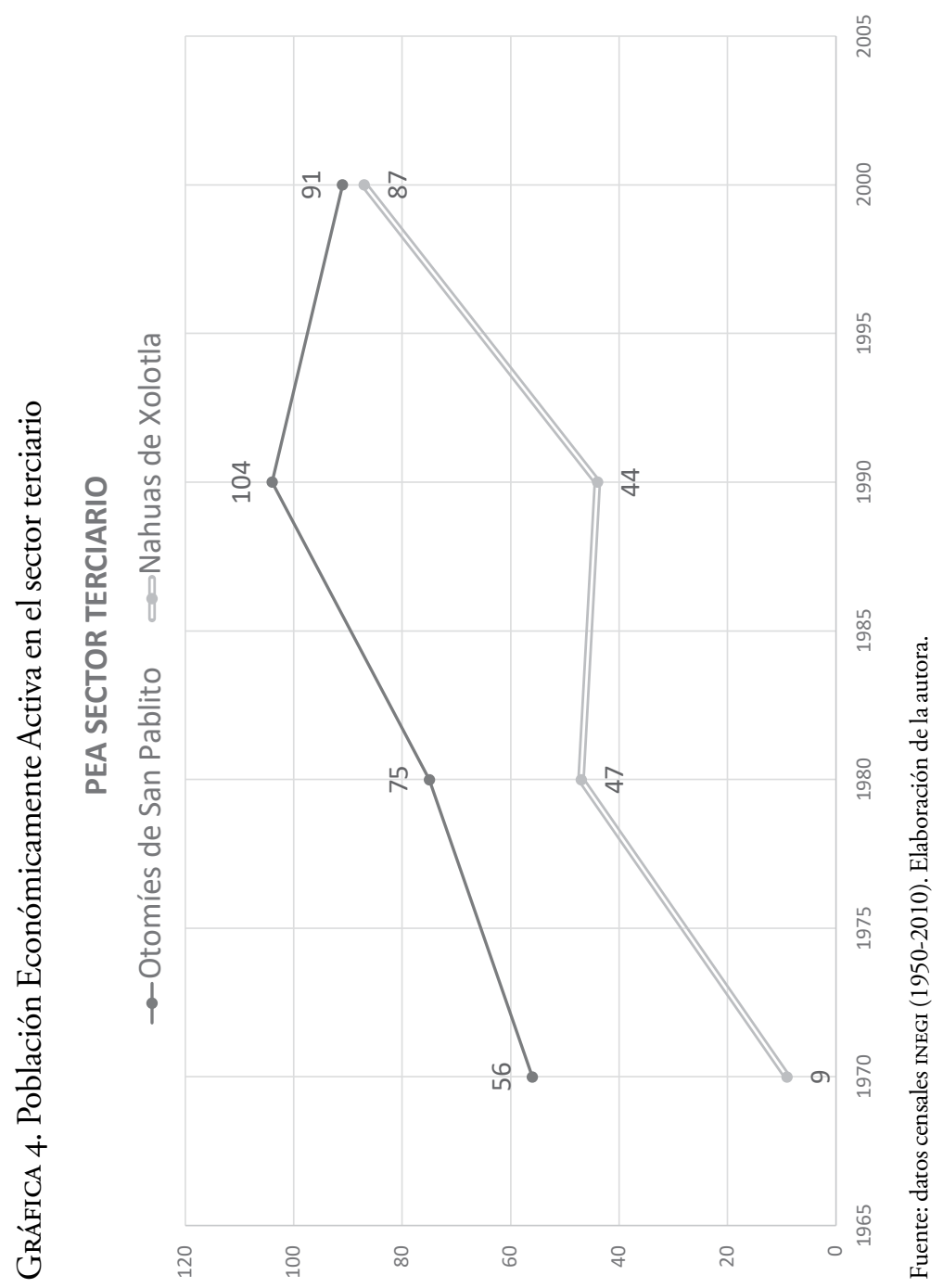


bién los contratan las mujeres que están solas y se dedican a vender artesanía en distintos puntos del país. Por otro lado, una vez que están de vuelta, los migrantes se emplean como taxistas. Con el ahorro de su sueldo como trabajador, los migrantes también pueden comprar un terreno, edificar su casa, poner un negocio local (papelería, internet, tienda de abarrotes), o invertir en su taller y negocio artesanal, ahora incluso denominados "galerías artesanales".

Por su parte, las mujeres también emigran, aunque ellas comenzaron a finales de los noventa y, la mayoría de ellas, ya entrado el nuevo milenio. Ellas se emplean en la industria de alimentos o, con más frecuencia, en labores domésticas, y cuidado de niños y ancianos de familias estadounidenses o mexicanas. Tanto para hombres como para mujeres, las redes y contactos son vitales. Antes de salir de su comunidad, muchos sanpableńos ya tienen "apalabrada la chamba" gracias a la recomendación de sus familiares y amigos que se encuentran en aquel país.

\section{ReFLEXIONES FINALES}

En este artículo he buscado mostrar un panorama de las dinámicas económicas en las que participaron los indígenas nahuas de Xolotla y otomíes de San Pablito, ambos del municipio de Pahuatlán, tomando como periodo de análisis el que va de los sesenta del siglo pasado a la primera década del nuevo milenio. El recorrido contempló la arriería y el comercio agrícola regional, seguido de actividades como la cafeticultura, la floricultura y la artesanía, así como una serie de movilidades laborales y la migración transnacional. Son muchas las aristas que se podrían destacar de cada una de esas alternativas, sin embargo, en el documento precisé sólo algunos aspectos, señalando grosso modo las características de cada una de las actividades y las relaciones sociales inmersas en campos sociales regionales, así como transnacionales. Antes de concluir este esbozo de dos casos de economía indígena contemporánea en la Huasteca poblana, a manera de reflexiones finales me ocupo aquí de un par de interrogantes. ¿Por qué investigar y analizar dos casos de estudio? ¿Por qué a través del enfoque de la nueva ruralidad? 
Expuse el caso de dos comunidades de filiación étnica distinta y de la misma zona, con la intención de mostrar las posibles similitudes y diferencias culturales que subyacen en las diferentes alternativas económicas que han imperado en esos grupos. Tal como quise demostrar, existen diferencias marcadas entre indígenas y mestizos, pero también entre otomíes y nahuas. Esto responde, en primera instancia, a factores socioculturales, seguidos de los económicos, y no al revés, como se suele suponer. Son precisamente las decisiones de grupo, es decir, las culturales, las que influyen en la toma de decisiones individuales y familiares, sin dejar de lado el contexto estructural o global que en efecto permea o constrińe aquellas decisiones. Son, por supuesto, los actores locales, en este caso los nahuas y otomíes, quienes definen bajo una lógica cultural de qué forma responder a esas demandas y condiciones. Negar esa capacidad de agencia es omitir precisamente toda una serie de procesos que han ido gestando a lo largo de cinco décadas, en las que, más que una posición de subordinación y pobreza, se destaca el papel activo que han desempeñado.

Sobre los mestizos hay que advertir que no han sido partícipes de todas las pluriactividades que han caracterizado a uno u otro grupo indígena. Incluso en el caso de los mestizos catalogados como pobres, éstos se han visto marginados al intentar trabajar en alguno de los oficios característicos de los indígenas, por ejemplo, la artesanía otomí, pues, se sabe que ésta es una actividad exclusiva de la región. Aunque otros grupos conozcan las técnicas de elaboración de la artesanía, los lugareños dicen "ésa es de San Pablito y después de los de Xochimilco, ahí ni meterse". ${ }^{92} \mathrm{Si}$ he dicho que los otomíes sanpableños contratan a destajo a mujeres mestizas, debe subrayarse que ellas elaboran alguna artesanía, pero difícilmente se aventurarían a emprender su propia empresa de comercialización, acaparada por los otomíes.

El grupo nahua ha podido incursionar de la misma forma que los otomíes sanpableños en el circuito migratorio transnacional.

${ }^{92}$ Xochimilco es una de las tres comunidades otomíes de Pahuatlán. Es colindante con San Pablito y, hasta hace siete décadas, formaba parte de la misma comunidad. 
Cuentan con las redes que, sin duda, facilitarían conseguir trabajo y poder cruzar la frontera. Sin embargo, en este grupo predomina la elección de no pasar largos periodos fuera de la comunidad; optan por dedicarse al campo, ya sea el café o bien innovar con otro cultivo que les permita generar una serie de actividades en la misma comunidad. Por otro lado, las mujeres nahuas, a diferencia de las otomíes, no se inclinan por probar suerte en los Estados Unidos; ellas no emigran y los hombres nahuas consideran prudente -incluso decente- esta decisión. La floricultura les permite trabajar y aunque sí implica una movilidad, están de vuelta al poco tiempo con la familia y en la comunidad. Las féminas otomíes, por su parte, no sólo tienen una experiencia de tres o cuatro décadas comercializando sus artesanías en distintas partes del país; ellas han emigrado solas, con sus hijos menores o con esposos a los Estados Unidos. Por último, la noción de territorio también varía entre ambos grupos, por ejemplo, en el caso del ámbito festivo, se observó que para los nahuas de Xolotla, hacer comunidad significa, literalmente, estar ahí, en contraste con la noción de comunidad transnacional otomí, en la que pueden seguir haciendo y siendo parte de ésta, incluso a la distancia. Estos elementos son un indicio de las variaciones culturales que se deben considerar para poder explicar las condiciones de subsistencia de los grupos indígenas, no solamente los contextos macroestructurales.

A partir del trabajo etnográfico se puede observar que en estos pueblos la actividad económica primordial ya no es la agricultura. Ésta mantiene su relevancia tanto en el ciclo agrícola como en el festivo, pero es claro que no es el único ni el principal medio de subsistencia económica de los grupos étnicos de Pahuatlán. Los otomíes y nahuas subsisten social y culturalmente gracias a una pluralidad de actividades: la pluriactividad en la que puede distinguirse la movilidad laboral, el comercio artesanal, la floricultura, los oficios libres, además de los apoyos gubernamentales y, recientemente, el turismo cultural. Participan hombres y mujeres, mayores y menores de edad, en una u otra labor, cada uno con un papel al interior de las unidades domésticas. Se reconfiguran, así, tanto las relaciones de género como las relaciones generacionales en las comunidades o es- 
pacios transnacionales. Retomando a Ariel de Vidas, ${ }^{93}$ puedo decir que estos procesos de cambio entre las colectividades indígenas contemporáneas no deben analizarse como amenaza a las identidades étnicas. Por el contrario, según procuré demostrar, estos procesos glocales reconfiguran y destacan las distinciones culturales.

Con la certeza de que el tema seguirá generando otras vertientes de análisis y será pertinente ahondar en mucho de las que he mencionado, cabe refrendar, por último, que me adhiero al enfoque de la nueva ruralidad porque permite, en mi opinión, identificar y cuestionar una serie de interrogantes entre los dos casos de estudio. Como lo sugiere la nueva ruralidad: se reconfigura el espacio, las identidades, los sujetos mismos. Los datos etnográficos permiten advertir cómo es que los pueblos indígenas están participando de manera activa en nuevos procesos glocales y, desde el marco de análisis de la nueva ruralidad, se destaca la capacidad de agencia de los grupos sociales. Partí de la idea de que los otomíes y nahuas no son meros sujetos pasivos ante el cambio o ciertas condiciones estructurales, sino que responden de manera activa y en función de sus especificidades culturales.

\section{BiBLIOGRAFÍA}

Aguirre Beltrán, Gonzalo. Regiones de refugio. El desarrollo de la comunidad y el proceso dominical en mestizoamérica. México: uv, INI, Gobierno del Estado de Veracruz, Fondo de Cultura Económica, 1991.

Appendini, Kirsten. "La transformación de la vida rural en tres ejidos de México". En ¿Ruralidad sin agricultura? Perspectivas multidisciplinarias de una realidad fragmentada, ed. Kirsten Appendini y Gabriela Torres-Mazuera, 27-57. México: El Colegio de México, 2008.

Aragonés, Ana María. "Migración y explotación de la fuerza de trabajo en los años noventa: saldos del neoliberalismo". En $E l$ sector agropecuario mexicano frente al nuevo milenio, coord. Blan-

${ }^{93}$ Anath Ariel de Vidas, "Prólogo", Trace (50) (2006): 1-30. 
ca Rubio, 239-268. México: IIs, Universidad Nacional Autónoma de México, Plaza y Valdés, 2004.

Arango, Joaquín. "La explicación teórica de las migraciones: luz y sombra”. Migración y Desarrollo (1) (2003): 1-30.

ArIas, Patricia. "Nueva ruralidad: antropólogos y geógrafos frente al campo hoy". En Lo urbano-rural, ¿nuevas expresiones territoriales?, coord. Héctor Ávila Sánchez, 123-159. México: CRIM, Universidad Nacional Autónoma de México, 2005.

Ariel de Vidas, Anath. "Prólogo". Trace (50) (2006): 1-30.

Baudel Wanderley, Maria de Nazareth. "A ruralidade no Brasil moderno. Por um pacto social pelo desenvolvimento rural”. En ¿Una nueva ruralidad en América Latina?, comp. Norma Giarracca, 31-44. Buenos Aires: ClACSO, ASDI, 2001.

Bravo Marentes, Carlos. Arrieros somos: el sistema de arriería de la Sierra Norte de Puebla. México: DGCP, Conaculta, 1988.

C. DE Grammont, Hubert. "La nueva ruralidad en América Latina”. Revista Mexicana de Sociología (66) (2004): 279-300.

. "El concepto de nueva ruralidad". En La nueva ruralidad en América Latina, comp. Edelmira Pérez C., María Adelaida Farah y Hubert C. de Grammont, 23-44. Bogotá: Clacso, Pontificia Universidad Javeriana, 2008.

C. De Grammont, Hubert y Héctor Tejera, coords. La sociedad rural mexicana frente al nuevo milenio. México: Plaza y Valdés, UAM, Universidad Nacional Autónoma de México, Instituto Nacional de Antropología, 1996.

Chamoux, Marie-Noëlle. Nahuas de Huauchinango: transformaciones sociales en una comunidad campesina. Trad. Luz María Santamaría. México: INI, CEMCA, México, 1987.

Dow, James W. Santos y supervivencias. Trad. Antonieta S.M. de Hope. México: INI, 1974.

Durand, Jorge, Douglas S. Massey y Emilio Parrado. “The New Era of Mexican Migration to the United States". Journal of American History 86(2) (1999): 518-536.

Eikeland, Sveinung. "New Rural Pluriactivity? Household Strategies and Rural Renewal in Norway". Sociologia Ruralis 39(3) (1999): 359-376. 
Flores Cruz, Ramiro A. "La discusión en torno a la migración y la movilidad territorial de la población”. http://www.iigg.fsoc.uba. ar/pobmigra/archivos (Fecha de consulta: 5 de abril de 2017).

Galinier, Jacques. "Iconografía otomí y nomadismo del sujeto". Alteridades 21(42) (2011): 165-175.

García Martínez, Bernardo. Los pueblos de la sierra: el poder y el espacio entre los indios del norte de Puebla hasta 1700. México: El Colegio de México, 1987.

GiarraccA, Norma y Bettina Levy. "Introducción. América Latina, nuevas ruralidades, viejas y nuevas acciones colectivas". Ruralidades latinoamericanas. Identidades y luchas sociales, comp. Norma Giarracca y Bettina Levy, 13-39. Buenos Aires: Clacso, 2004.

Gómez E., Sergio. La “nueva ruralidad”: ¿Quétan nueva? Revisión de la bibliografía, un intento por definir sus limites y una propuesta conceptual para realizar investigaciones. Santiago: Universidad Austral de Chile, 2002.

Gómez, Sergio. "Nueva ruralidad (fundamentos teóricos y necesidad de avances empíricos)". Documento de trabajo presentado en el Seminario Internacional El Mundo Rural: Transformaciones y Perspectivas a la Luz de la Nueva Ruralidad, Bogotá, Colombia, octubre 15-17, 2003.

GonzÁlez y González, Luis, Fernán González y Martín GonzÁLEz. "Entrevista de Enrique Krauze. 'Gente del campo"”. Vuelta (151) (1989): 22-29.

Govers, Cora. Performing the Community: Representation, Ritual and Reciprocity in the Totonac Highlands of Mexico. Münster: LIT VERLAG Berlin, 2006.

Grajales Ventura, Sergio y Luciano Concheiro Bórquez. "Nueva ruralidad y desarrollo territorial. Una perspectiva desde los sujetos sociales". Veredas (18) (2009): 145-167.

Hjorth Boisen, Susann Vallentin. "Migración, globalización y flujos transregionales. Etnografía del proceso migratorio del sur de Veracruz a la frontera norte". Tesis Doctoral, Universidad Nacional Autónoma de México, 2007.

ICHON, Alain. La religión de los totonacas de la sierra. Trad. José Arenas. México: INI, 1973. 
KaY, Cristóbal. "Estudios rurales en América Latina en el periodo de globalización neoliberal: ¿una nueva ruralidad?” Revista Mexicana de Sociología 71(4) (2009): 607-645.

KEARney, Michael. Reconceptualizing the peasantry: Anthropology in global perspective. Boulder: Westview Press, 1996.

Lenz, Hans. El papel indigena mexicano. México: Secretaría de Educación Pública, 1973.

León López, Arturo y Cristina STEFFen. Ganadería y granos básicos en la Sierra Norte de Puebla: una lucha desigual. México: UAM Xochimilco, 1987.

LÉvi-Strauss, Claude. Antropología estructural. Trad. Eliseo Verón. Barcelona: Altaya, 1994.

Llambí InsuA, Luis. "Globalización y nueva ruralidad en América Latina: una agenda teórica de investigación”. ALASRU. Revista Latinoamericana de Sociología Rural (2) (1994): 29-39.

Martínez, Cristina. "Transformación de la actividad cafetalera en los años noventa”. En El sector agropecuario mexicano frente al nuevo milenio, coord. Blanca Rubio, 109-146. México: IIs, Universidad Nacional Autónoma de México, Plaza y Valdés, 2004. Masferrer Kan, Elio. Los dueños del tiempo. Los tutunakú de la Sierra Norte de Puebla. México: Fundación Juan Rulfo, 2009.

Montoya Briones, José de Jesús. Atla. Etnografía de un pueblo náhuatl. México: Instituto Nacional de Antropología, 1964.

Mora Martínez, Libertad. "Reconfiguraciones culturales y estrategias de sobrevivencia otomí, en San Pablito, Pahuatlán”. Tesis de Licenciatura en Antropología Social, Benemérita Universidad Autónoma de Puebla, Ciesas, 2008.

. "Dinámicas migratorias en Pahuatlán: municipio de indígenas y mestizos en la Sierra Norte de Puebla (1980-2010)”. Tesis de Maestría en Antropología Social, Ciesas Golfo, 2011.

. "Huauchinango: vida y resignificaciones del pasado". En Huauchinango el rumor del tiempo, coord. Libertad Mora, 275298. Puebla: H. Ayuntamiento de Huauchinango 2011-2014, PIRED, 2011.

- "Por un proyecto en el que los indígenas sean protagonistas de su cultura". La Jornada de Oriente, 15 de octubre de 2015. 
. "De la Sierra a la Costa. Migración otomí transnacional: Los hñähñü de la Huasteca Poblana”. Migraciones Internacionales 9(34) (2018): 9-36.

Murdoch, Jonathan y Andy C. Pratt. "Rural Studies: Modernism, Postmodernism and the 'Post-rural'". Journal of Rural Studies 9(4) (1993): 411-427.

Palacios Urueta, Julio Mario. "Movimiento campesino en el sur de Santander. Una lucha por el acceso a la modernidad”. Tesis de Maestría en Antropología Visual y Documental Antropológico, FLACSO Ecuador, 2013.

PARÉ, Luisa. "Caciquismo y estructura de poder en la Sierra Norte de Puebla”. En Caciquismo y poder politico en el México rural. Roger Bartra, Eckart Boege, Pilar Calvo, Jorge Gutiérrez, Víctor Raúl Martínez Vázquez, Luisa Paré, 31-61. México: Siglo XXI, 1976.

PÉrez C., Edelmira. "Hacia una nueva visión de lo rural”. En ¿Una nueva ruralidad en América Latina?, compilado por Norma Giarracca, 17-29. Buenos Aires: CLACSO, ASDI, 2001.

Rubio, Blanca. "El sector agropecuario mexicano en los años noventa: subordinación desestructurante y nueva fase productiva”. En Elsector agropecuario mexicano frente al nuevo milenio, coord. Blanca Rubio, 17-45. México: IIS, Universidad Nacional Autónoma de México, Plaza y Valdés, 2004.

SAndstrom, Alan R. y Pamela Effrein SAndstrom. Traditional papermaking and paper cult figures of Mexico. Norman: University of Oklahoma Press, 1986.

Skerritt Gardner, David. Campesinos: ¿de qué hablamos? Xalapa: IIHS, UV, 1998.

STRESSER-PÉAN, Guy. Los lienzos de Acaxochitlán (Hidalgo) y su importancia en la historia del poblamiento de la Sierra Norte de Puebla y zonas vecinas. Trad. Araceli Méndez y Angelines Torres. México: IHEMSYS, CECA, Gobierno del Estado de Hidalgo, CEMCA, 1998. . El Sol-Dios y Cristo. La cristianización de los indios de México vista desde la Sierra de Puebla. Trad. Roberto Rueda Monreal y Arturo Vázquez Barrón. México: Fondo de Cultura Económica, Conaculta, CEMCA, 2011.

Tocancipá-Falla, Jairo. "El retorno de lo campesino: una revisión 
sobre los esencialismos y heterogeneidades en la antropología”. Revista Colombiana de Antropología (41) (2005): 7-41.

VÁzQuez y De Los Santos, Elena. Los Tenangos. Mitos y ritos bordados. Arte textil hidalguense. México: Conaculta, 2008.

Velázquez Hernández, Emilia. Cuando los arrieros perdieron su camino. La conformación regional del Totonacapan. Zamora: El Colegio de Michoacán, 1995.

Warman, Arturo. Ensayos sobre el campesinado en México. México: Nueva Imagen, 1980.

Wolf, Eric R. Los campesinos. Barcelona: Labor, 1987.

. Las luchas campesinas del siglo XX. Trad. Roberto Reyes Mazzoni. México: Siglo XXI, 1999.

Wuest Silva, Tania Jeanine. “¿Nueva Ruralidad en México?” Tesis de Licenciatura en Sociología, UAM, 2004. 